Published in final edited form as:

Biochemistry. 2020 February 04; 59(4): 582-593. doi:10.1021/acs.biochem.9b00953.

\title{
Evolution of Substrates and Components of the Pro/N-Degron Pathway
}

\author{
Shun-Jia Chen, Artem Melnykov ${ }^{\dagger}$, Alexander Varshavsky $^{\star}$ \\ Division of Biology and Biological Engineering, California Institute of Technology, Pasadena, \\ California 91125, United States
}

\section{Abstract}

Gid4, a subunit of the ubiquitin ligase GID, is the recognition component of the Pro/N-degron pathway. Gid4 targets proteins in particular through their N-terminal (Nt) proline (Pro) residue. In Saccharomyces cerevisiae and other Saccharomyces yeasts, the gluconeogenic enzymes Fbp1, Icl1, and Mdh2 bear Nt-Pro and are conditionally destroyed by the Pro/N-degron pathway. However, in mammals and in many non-Saccharomyces yeasts, for example, in Kluyveromyces lactis, these enzymes lack Nt-Pro. We used $K$. lactis to explore evolution of the Pro/N-degron pathway. One question to be addressed was whether the presence of non-Pro Nt residues in $K$. lactis Fbp1, Icl1, and Mdh2 was accompanied, on evolutionary time scales ( $S$. cerevisiae and $K$. lactis diverged $\sim 150$ million years ago), by a changed specificity of the Gid4 N-recognin. We used yeast-based two-hybrid binding assays and protein-degradation assays to show that the non-Pro (Ala) Nt residue of $K$. lactis Fbp1 makes this enzyme long-lived in $K$. lactis. We also found that the replacement, through mutagenesis, of Nt-Ala and the next three residues of $K$. lactis Fbp1 with the four-residue Nt-PTLV sequence of $S$. cerevisiae Fbp1 sufficed to make the resulting "hybrid" Fbp1 a short-lived substrate of Gid4 in K. lactis. We consider a blend of quasi-neutral genetic drift and natural selection that can account for these and related results. To the best of our knowledge, this work is the first study of the ubiquitin system in $K$. lactis, including development of the first protein-degradation assay (based on the antibiotic blasticidin) suitable for use with this organism.

\section{Graphical Abstract}

\footnotetext{
"Corresponding Author: avarsh@caltech.edu.

Author Contributions

S.-J.C., A.M., and A.V. designed the experiments. S.-J.C. and A.M. performed the experiments. S.-J.C., A.M., and A.V. wrote the paper. All authors discussed the results and commented on the manuscript.

Present Address: A.M.: Auragent Bioscience, Inc., St. Louis, MO 63108.

Supporting Information

The Supporting Information is available free of charge at https://pubs.acs.org/doi/10.1021/acs.biochem.9b00953.

N-Degron pathways (Figure S1), amino acid sequence alignments (Figure S2), inhibition of translation by blasticidin in $K$. lactis (Figure S3), results of RT-qPCR assays (Figure S4), verification of $K$. lactis strains (Figure S5), K. lactis strains (Table S1), and cited references (PDF)

The authors declare no competing financial interest.
} 


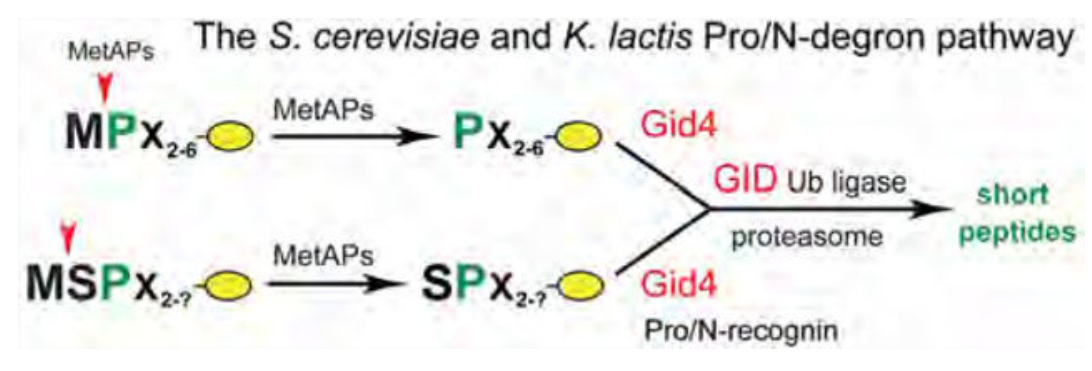

Regulated protein degradation protects cells from misfolded, aggregated, or otherwise abnormal proteins and also controls the levels of proteins that evolved to be short-lived in vivo. The intracellular protein degradation is mediated largely by the ubiquitin (Ub)proteasome system (UPS) and by autophagy-lysosome pathways, with molecular chaperones being a part of both systems. ${ }^{1-7}$ The UPS comprises a set of pathways that have in common at least two classes of enzymes: E3-E2 Ub ligases and deubiquitylases (DUBs).

A Ub ligase recognizes a substrate protein through its degradation signal (degron) and conjugates $\mathrm{Ub}$, a $9 \mathrm{kDa}$ protein (usually in the form of a poly-Ub chain), to an amino acid residue (usually an internal lysine) of a targeted substrate. The functions of DUBs include deubiquitylation of Ub-conjugated proteins. ${ }^{2-4,8,9}$ The $26 \mathrm{~S}$ proteasome, an ATP-dependent protease, binds to a polyubiquitylated protein through its poly-Ub chain, unfolds the protein, and converts it to $\sim 10$-residue peptides. ${ }^{10-15}$

$\mathrm{N}$-degron pathways (previously called "N-end rule pathways") are a set of proteolytic systems whose unifying feature is their ability to recognize proteins containing N-terminal (Nt) degrons called $\mathrm{N}$-degrons, thereby causing the degradation of these proteins by the $26 \mathrm{~S}$ proteasome and/or autophagy in eukaryotes, and by the proteasome-like ClpAP protease in bacteria (Figure S1) ${ }^{2,16-43}$ Determinants of an N-degron comprise, in particular, a destabilizing $\mathrm{Nt}$ residue of a protein substrate and its internal Lys residue (or residues) that can act as a polyubiquitylation site. , $^{2,17,44}$

Initially, most $\mathrm{N}$-degrons are cryptic (pro-N-degrons). They are converted to active $\mathrm{N}$ degrons either constitutively (e.g., during the emergence of a protein from a ribosome) or via regulated steps. Among the routes to $\mathrm{N}$-degrons are cleavages of proteins by proteases such as, for example, caspases or calpains. ${ }^{29,45,46}$ By cleaving a protein and exposing a destabilizing $\mathrm{Nt}$ residue in a $\mathrm{C}$-terminal $(\mathrm{Ct})$ fragment, these and other nonprocessive proteases function as components of $\mathrm{N}$-degron pathways. Another route to active $\mathrm{N}$-degrons is through enzymatic $\mathrm{Nt}$ modifications of proteins, including $\mathrm{Nt}$ acetylation, $\mathrm{Nt}$ deamidation, $\mathrm{Nt}$ oxidation, $\mathrm{Nt}$ arginylation, $\mathrm{Nt}$ leucylation, and $\mathrm{Nt}$ formylation. Recognition components of N-degron pathways, called N-recognins, are either E3 Ub ligases or other proteins (e.g., bacterial ClpS or mammalian p62) that can target N-degrons. ${ }^{2,6,19,20,38}$ All 20 amino acids of the genetic code have been shown to function, in cognate sequence contexts, as destabilizing Nt residues (Figure S1). Thus, many proteins in a cell are conditionally shortlived $\mathrm{N}$-degron substrates, either as full-length proteins or as protease-generated $\mathrm{Ct}$ fragments. 
Eukaryotic N-degron pathways comprise the Arg/N-degron pathway [it recognizes, in particular, specific unacetylated Nt residues (Figure S1A)], the Ac/N-degron pathway [it recognizes, in particular, the $\mathrm{N}^{a}$-terminally acetylated (Nt-acetylated) $\mathrm{Nt}$ residues (Figure S1B)], the Pro/N-degron pathway [it recognizes, in particular, the Nt-Pro residue (Figure S1C)], the Gly/N-degron pathway (it recognizes the unmodified Nt-Gly residue), and the $\mathrm{fMet} / \mathrm{N}$-degron pathway (it recognizes $\mathrm{Nt}$-formylated cellular proteins). ${ }^{2,18-20,22,23,43}$

Regulated degradation of proteins and their natural $\mathrm{Ct}$ fragments by $\mathrm{N}$-degron pathways has been shown to mediate a multitude of processes, including the sensing of oxygen, nitric oxide, heme, and short peptides; the control of subunit stoichiometries in protein complexes; the elimination of misfolded proteins and of proteins retrotranslocated to the cytosol from other compartments; the repression of neurodegeneration and regulation of apoptosis; the control of DNA damage responses, transcription, replication, and chromosome cohesion/ segregation; the regulation of chaperones, G proteins, cytoskeletal proteins, autophagy, gluconeogenesis, peptide transport, meiosis, circadian rhythms, fat metabolism, cell migration, the adaptive and innate immunity (including inflammation), the cardiovascular system, neurogenesis, and spermatogenesis; and also regulation of plant defenses against pathogens, differentiation of plant cells, the sensing of oxygen, and many other processes in plants (refs 2, 16, 18-28, 30, 32-43, and 47 and references therein).

Under conditions with little or no glucose, the yeast Saccharomyces cerevisiae and other eukaryotes synthesize glucose through gluconeogenesis. In $S$. cerevisiae, the main gluconeogenesis-specific cytosolic enzymes are the Fbp1 fructose-1,6-bisphosphatase, the Icl1 isocitrate lyase, the Mdh2 malate dehydrogenase, and the Pck1 phosphoenolpyruvate carboxykinase. ${ }^{24,48-59}$ When $S$. cerevisiae grows on a nonfermentable carbon source such as, e.g., ethanol, gluconeogenic enzymes are expressed and relatively long-lived. A shift to a medium containing glucose represses the synthesis of these enzymes and induces their degradation. Degradation of gluconeogenic enzymes in $S$. cerevisiae requires the multisubunit GID Ub ligase. ${ }^{40,52,53,56,60,61}$ A notable aspect of GID-mediated processes is the dichotomy between the GID/proteasome-mediated degradation of gluconeogenic enzymes and their "alternative" degradation through an autophagy-related vacuolar import and degradation (VID) pathway. ${ }^{53,56,59,62}$ Whether these enzymes are destroyed (after a return of $S$. cerevisiae to glucose-containing media) largely by the GID/proteasome route or largely by the GID/VID route depends, among other things, on the nature of a nonfermentable carbon source and the duration of glucose starvation..$^{50,63}$

S. cerevisiae Gid4 is a $41 \mathrm{kDa}$ subunit of the GID Ub ligase. ${ }^{61}$ We have shown that Gid4 and the related (stress-inducible) Gid10 protein are the N-recognins of the GID-mediated proteolytic system termed the Pro/N-degron pathway (Figure S1C). 2,24,64 Gid4 recognizes a substrate through its Nt-Pro residue or a Pro at position 2, in the required presence of adjoining sequence motifs. ${ }^{24,26}$ S. cerevisiae gluconeogenic enzymes bear either an Nt-Pro (Fbp1, Icl1, and Mdh2) or a Pro at position 2 (Pck1). These enzymes are conditionally shortlived substrates of the Pro/N-degron pathway (Figure S1C). ${ }^{24,26,61}$ The structure of human Gid 4 comprises an antiparallel $\beta$-barrel that contains a substrate binding cleft. ${ }^{25,26} \mathrm{In}$ mammals, the GID Ub ligase (also called CTLH) functions in primary cilia, in cell proliferation, and in other processes. ${ }^{60,65-73}$ 
The subphylum of budding yeasts emerged $\sim 500$ million years ago (mya). Roughly 100 mya, an ancestor of budding yeast lineages that include $S$. cerevisiae and other Saccharomyces yeasts underwent a whole genome duplication. ${ }^{74-78}$ Counterparts of Gid4 and other subunits of the $S$. cerevisiae GID Ub ligase are present in most eukaryotes, including Kluyveromyces lactis, a non-Saccharomyces budding yeast whose lineage did not undergo a whole genome duplication. The last common ancestor of $S$. cerevisiae and $K$. lactis lived roughly 150 mya. ${ }^{74-76}$

Gluconeogenic enzymes of $K$. lactis are highly sequelogous (similar in sequence ${ }^{79}$ ) to their $S$. cerevisiae counterparts (Figure S2A). However, in contrast to $S$. cerevisiae Fbp1, Icl1, and $\mathrm{Mdh} 2$, the Nt residues of the sequelogs of these enzymes in $K$. lactis are not Nt-Pro (Figure $\mathrm{S} 2 \mathrm{~A}-\mathrm{C}$ ). For example, the Nt residue of $K$. lactis Fbp1 is Ala (Figure S2A). These differences make genetically tractable $K$. lactis a helpful setting for exploring evolution of the Pro/N-degron pathway. ${ }^{\text {a }}$

To the best of our knowledge, this paper describes the first study of the Ub system in $K$. lactis, including development of the first protein-degradation assay suitable for use with this organism. In contrast to ribosomes of most other eukaryotes, $K$. lactis ribosomes are resistant to cycloheximide. ${ }^{80}$ Therefore, to enable this project, we devised a chasedegradation assay that works in $K$. lactis and employs the blasticidin antibiotic to inhibit translation (Figure S3).

Among the questions addressed in this study is whether non-Pro Nt residues of $K$. lactis Fbp1, Icl1, and Mdh2 were accompanied, on evolutionary time scales ( $S$. cerevisiae and $K$. lactis diverged roughly 150 mya), by a changed specificity of the Gid4 N-recognin or whether $K$. lactis Gid4 is, in fact, Nt-Pro-specific (similar to $S$. cerevisiae Gid4) and therefore unable to target the $K$. lactis enzymes mentioned above. We answer this question by showing, in particular, that the non-Pro (Ala) Nt residue of $K$. lactis Fbp1 makes this enzyme long-lived in $K$. lactis and also by showing that the replacement, through mutagenesis, of Nt-Ala and the next three residues of $K$. lactis Fbp1 with the four-residue Nt-PTLV sequence of $S$. cerevisiae Fbp1 is sufficient for the resulting "hybrid" Fbp1 to become a short-lived substrate of Gid4 in K. lactis. The demonstrated metabolic stability of, in particular, K. lactis Fbp1, owing to its Nt-Ala (instead of Nt-Pro in S. cerevisiae), illustrates aspects of evolution that are likely to result not from selection pressures but from a quasi-random genetic drift that is not opposed strongly enough by natural selection, in such cases. This work would facilitate analogous comparisons between, e.g., yeast and mammalian Pro/N-degron pathways, because the N-termini of mammalian non-Pck1 gluconeogenic enzymes are also distinct from their $S$. cerevisiae counterparts.

\footnotetext{
a"Sequelog" denotes a sequence that is similar, to a specified extent, to another sequence. ${ }^{79}$ Derivatives of "sequelog" include "sequelogy" (sequence similarity) and "sequelogous" (similar in sequence). The usefulness of "sequelog" and derivative notations stems from the rigor and clarity of their evolutionary neutrality. By contrast, in settings that use "homolog", "ortholog", and "paralog" (they denote common descent and functional similarity and dissimilarity, respectively), these terms are often interpretation-laden and therefore imprecise. The homolog, ortholog, and paralog are compatible with the sequelog terminology. The former terms can be used to convey understanding of common descent and biological functions, if this additional information, distinct from sequelogy per se, is actually present. ${ }^{79}$
} 


\section{MATERIALS AND METHODS}

\section{Antibodies and Other Reagents.}

The following primary antibodies were used for immunoblotting: anti-hemagglutinin (ha) tag monoclonal antibody (Sigma, H6908), anti-cMyc-9E10 monoclonal antibody (Sigma, M5546), and anti-flag M2 monoclonal antibody (Sigma, F1804). Secondary antibodies for immunoblotting were Li-Cor IRDye-conjugated goat anti-rabbit 680RD (Li-Cor, C5110408) and anti-mouse 800CW (Li-Cor, C60405-05). Fluorescence was detected and quantified using an Odyssey 9120 instrument (Li-Cor, Lincoln, NE). The UltraCruz protease inhibitor cocktail tablet (EDTA-free) was from Santa Cruz Biotechnology. A variety of restriction enzymes (used for plasmid construction), T4 DNA ligase, and Q5 DNA polymerase were from New England Biolabs. Tetracycline (Tc) and glucose were from Sigma.

\section{S. cerevisiae and $K$. lactis Yeast Strains.}

The following $S$. cerevisiae strains were used in this study: BY4741 (MATa his3 1

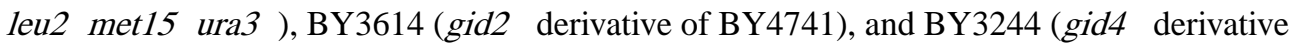
of BY4741). Standard techniques were used to construct plasmids and yeast strains. ${ }^{81,82}$ The AH109 S. cerevisiae strain (MATa, trp1-901, leu2-3, 112, ura3-52, his3-200, gal4A,

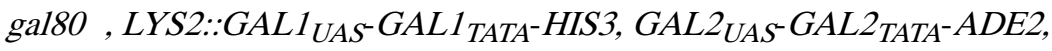
URA3::MEL1 $1_{U A S}-M E L 1_{T A T A}-\mathrm{lacZ}$ ) was used for two-hybrid (Y2H) binding assays.

Yeast media (used for growing either $S$. cerevisiae or $K$. lactis) included YPD medium (1\% yeast extract, $2 \%$ peptone, and $2 \%$ glucose), SC medium ( $0.17 \%$ yeast nitrogen base, $0.5 \%$ ammonium sulfate, and $2 \%$ glucose, supplemented with compounds required by auxotrophic yeast strains), and SE medium (the same as SC medium but with $2 \%$ ethanol instead of glucose). The alternative carbon sources, in either liquid or plate media, were $2 \%$ ethanol (YPE and SE media) or $2 \%$ potassium acetate (YPKA and SKA media). The yeast nitrogen base with ammonium sulfate and the supplement mixtures of amino acids for $S$. cerevisiae and $K$. lactis growth were from MP Biomedicals. Yeast extract and yeast peptone were from Difco.

All $K$. lactis strains used in this study were derived from the parental (Dombrowski) van der Walt strain [American Type Culture Collection (ATCC), 8585] and are listed in Table S1. K. lactis strains were constructed by electroporation of the parental strain with PCR-generated DNA fragments containing long ( $400 \mathrm{bp}$ ) homology segments (nearly 10-fold longer than analogous homology segments with $S$. cerevisiae) directed to the genomic DNA locus of interest. ${ }^{83,84}$ Plasmid pFA6a-natNT2 contained the dominant marker natNT2, a derivative of the natMX4 gene that confers resistance to nourseothricin. ${ }^{85}$ In the K. lactis yCSJ24 (gid4A) strain (Table S1), a (complete) deletion gid $4 \Delta$ allele contained integrated natNT2. With pFA6a-natNT2 as the PCR template, several oligonucleotide primers and a few sequential PCR amplifications were used to construct a natNT2-containing deletion/disruption gid4A DNA fragment that also contained $\sim 400$ bp flanking DNA segments. That DNA fragment was transformed, by electroporation, into the parental $K$. lactis strain, followed by selection for cells resistant to nourseothricin and verification of the resulting gid $4 \Delta$ allele. 
The yCSJ25 K. lactis strain (Table S1) was constructed in a manner analogous to that of yCSJ24, but instead of pFA6a-natNT2, the pFa6-KanMX6 plasmid, ${ }^{86,87}$ encoding resistance to Geneticin (G418), was used as the PCR template to generate a requisite DNA fragment. This yielded (after transformation of $K$. lactis, isolation of Geneticin-resistant transformants, and verification of the allele's correctness) an allele of the $K$. lactis FBP1 gene (KI-FBPI) that encoded the $\mathrm{C}$-terminally triple ha-tagged $K l$-Fbp $1_{3 \text { ha }}$ protein expressed from the native $\mathrm{P}_{\text {FBP1 }}$ promoter. The similarly constructed yCSJ27 K. lactis strain (Table S1) expressed the same $K 1$-Fbp $1_{3 \text { ha }}$ in the gid $4 \Delta$ genetic background. The same approaches, using the pFa6KanMX6 plasmid, were used to construct $K$. lactis yCSJ29 and yCSJ31 (Table S1). The yCSJ29 strain expressed $K l-\mathrm{Pck} 1_{3 \text { ha }}$ from the native $\mathrm{P}_{P C K 1}$ promoter. The otherwise identical yCSJ31 strain expressed $K l$-Pck $1_{3 \text { ha }}$ in the gid $4 \Delta$ background.

The $K$. lactis yCSJ47 strain was constructed in the background of yCSJ25 (Table S1). The PCR-generated DNA fragment used for transformation of yCSJ25 was produced by employing the pFA6-HphNT1 plasmid ${ }^{85}$ as the PCR template, with PCR primers designed to encode Pro-Thr-Leu-Val (PTLV), the first four residues of $S$. cerevisiae Fbp1 ( $S c$-Fbp1) that replaced, in $K$. lactis, the first four residues of C-terminally tagged but otherwise wild-

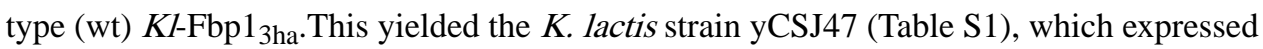
ptlv-Fbp $1_{3 \mathrm{ha}}$ from the native $\mathrm{P}_{F B P 1}$ promoter (see Results and Discussion) and was resistant to hygromycin-B. The otherwise identical $K$. lactis yCSJ48 strain (Table S1) was produced in the gid $4 \Delta$ background. The $K$. lactis yCSJ49 strain expressed the N-terminally myc9tagged $K$. lactis myc $9_{9}$ Gid4 from the native $\mathrm{P}_{\text {GID4 }}$ promoter (Table S1). (Kl-Gid4 was tagged $\mathrm{N}$-terminally because a C-terminally tagged Gid4 is not functional at least in $S$. cerevisiae.

${ }^{24}$ ) yCSJ49 was constructed in a manner analogous to the procedures described above, in the background of the gid $4 \Delta$ yCSJ49 strain, which contained the deletion/disruption gid $4 \Delta$ NatNT2 allele, resulting in its replacement by the ${ }_{\text {myc }}$ Gid4-HphNT1 allele that encoded $K$. lactis myc9$_{9}$ Gid4 expressed from the native $\mathrm{P}_{\text {GID4 }}$ promoter (Table $\mathrm{S} 1$ ).

\section{Construction of Plasmids.}

Escherichia coli strains SUREII (Stratagene), DH5a, and STBL2 (Invitrogen) were used for cloning and maintaining plasmids. PCR was carried out using Phusion High-Fidelity DNA polymerase and Q5 DNA polymerase (New England Biolabs).

For quantifying the degradation of specific proteins in $S$. cerevisiae, we employed Tc/PRTchase-degradation assays (see Results and Discussion). Plasmids for these assays used pJO629 as the parental plasmid and were constructed as previously described. ${ }^{24,40}$ Briefly, to construct pCSJ949, which expressed the C-terminally triple-flagged $K$. lactis $\mathrm{Fbp}_{3 \mathrm{f}}(\mathrm{Kl}$ $\mathrm{Fbp}_{3 \mathrm{f}}$ ) in $\mathrm{S}$. cerevisiae from the $\mathrm{P}_{T D H 3}$-based promoter, a $\mathrm{Kl}$-Fbp1-encoding DNA fragment was amplified by PCR from $K$. lactis genomic DNA using the primers CSJ930 and CSJ931. The resulting PCR product was digested with $A s c \mathrm{~L} / \mathrm{BamHI}$ and ligated into $\mathrm{Ascl} / \mathrm{BamHI}$-cut pJO629 downstream of its $\mathrm{P}_{T D H 3}$-based promoter, yielding pCSJ949. To construct pCSJ974, which expressed the C-terminally triple-flagged $K$. lactis $\mathrm{Pck}_{3 \mathrm{f}}\left(K l\right.$-Pck $\left.1_{3 \mathrm{f}}\right)$ in $S$. cerevisiae from the $\mathrm{P}_{T D H 3}$-based promoter, the $K I-P C K l_{3 \mathrm{f}}$-encoding DNA fragment was produced by a two-step PCR from K. lactis genomic DNA, using, initially, the primers CSJ991 and CSJ992 and thereafter the primers CSJ991 and CSJ182. The resulting PCR product was digested 
with AscI/NotI and ligated into AscI/Notl-cut pJO629, yielding pCSJ974. The pCSJ976 plasmid, which expressed $K$. lactis Gid4 N-terminally tagged by the myc ${ }_{9}$ tag $\left(\mathrm{Kl} \mathrm{-}_{9 \mathrm{myc}} \mathrm{Gid} 4\right)$, was constructed like the plasmids described above. Additional details are available upon request. Construction of plasmids for two-hybrid (Y2H) assays is described below. All final constructs were verified by DNA sequencing.

\section{Y2H Binding Assays.}

The AH109 S. cerevisiae strain was used for all $\mathrm{Y} 2 \mathrm{H}$ experiments (Figure 1). In one set of assays, $A H 109$ was cotransformed with pCSJ182 (NLS-Sc-Gid4 ${ }_{3 \mathrm{f}}-\mathrm{Gal} 4^{\mathrm{AD}}$ ) and either pCSJ165 [expressing (Met)-Pro-Sc-Fbp1-Ga14 ${ }^{\mathrm{DBD}}$ ] or pCSJ179 [expressing (Met)-Ser-ScFbp1-Gal4 ${ }^{\mathrm{DBD}}$ ], with " $S c$ " denoting $S$. cerevisiae proteins. In analogous tests with $K$. lactis Kl-Gid4, AH109 was cotransformed with pCSJ912 (expressing NLS-Kl-Gid4-Gal4 ${ }^{\mathrm{AD}}$ ) and either pCSJ165 or pCSJ179. Other Y2H assays (Figure 1) used pCSJ914 [expressing (Met)Ala-Kl-Fbp1-Gal4 ${ }^{\mathrm{DBD}}$ ] and pCSJ946 [expressing (Met)-Ser-Kl-Mdh2-Gal4 ${ }^{\mathrm{DBD}}$ ]. Inasmuch as the $\mathrm{Kl}$-Mdh2 open reading frame (ORF) encodes, at position 36, the in-frame second Met residue that is followed by the Pro residue (Figure S2B), Y2H assays included, in addition, the pCSJ947 plasmid, which expressed $\left(\mathrm{Met}^{36}\right.$ )-Pro ${ }^{37}-\mathrm{Kl}-\mathrm{Mdh} 2-\mathrm{Gal} 4^{\mathrm{DBD}}$ (Figure 1 and Figure S2B).

Cells cotransformed with Y2H-based plasmids were plated on [-Trp, -Leu] SC plates. Single colonies of resulting transformants were grown in the otherwise identical liquid medium to a near-stationary phase $\left(\mathrm{OD}_{600}\right.$ of $\left.\sim 2.0\right)$. The cells were serially diluted by 3 -fold, and $15 \mu \mathrm{L}$ samples of cell suspensions were spotted onto triple-dropout [-Trp, -Leu, -His] SC plates, ${ }^{88}$ followed by incubation at $30{ }^{\circ} \mathrm{C}$ for $2-3$ days. All transformants could grow on [-Trp, -Leu] SC, but only strains that expressed HIS3, a Y2H reporter, could grow on [-Trp, -Leu, -His] plates. ${ }^{89,90}$

\section{Promoter Reference Technique (PRT) Degradation Assays and Immunoblotting.}

The design of tetracycline (Tc)-based Tc/PRT chase-degradation assays ${ }^{24,40}$ is described in Results and Discussion. Briefly, batch yeast cultures were grown in SC medium overnight. Cells were centrifuged at $11200 \mathrm{~g}$ for $1 \mathrm{~min}$, washed once in prewarmed PBS buffer, then resuspended in either SE (ethanol as the carbon source) or SKA (acetate as the carbon source) to an $\mathrm{OD}_{600}$ of 0.5 , and allowed to grow in the respective media for $20 \mathrm{~h}$ at $30{ }^{\circ} \mathrm{C}$. Cells were collected by centrifugation and resuspended in fresh $\mathrm{SC}$ to the final $\mathrm{OD}_{600}$ of 1.0, with $\mathrm{Tc}$ at $0.5 \mathrm{mM}$, and the tube was incubated at $30^{\circ} \mathrm{C}$, with gentle rocking. At the indicated time intervals (including the beginning of the incubation), equal-volume samples were collected, and cells were pelleted by centrifugation. Cell pellets were resuspended in 1 $\mathrm{mL}$ of $1 \mathrm{M} \mathrm{NaOH}$ and incubated at room temperature for $5 \mathrm{~min}$. Cell were again collected by centrifugation (at the top speed in a microcentrifuge for $1 \mathrm{~min}$ ) and resuspended in $50 \mu \mathrm{L}$ of buffer HU [ $8 \mathrm{M}$ urea, 5\% SDS, $1 \mathrm{mM}$ EDTA, $0.1 \mathrm{M}$ dithiothreitol (DTT), 0.005\% bromophenol blue, and $0.2 \mathrm{M}$ Tris- $\mathrm{HCl}$ ( $\mathrm{pH}$ 6.8)]. These protein solutions were incubated at $70{ }^{\circ} \mathrm{C}$ for $10 \mathrm{~min}$. Samples were fractionated by SDS-PAGE on 4- to $12 \%$ NuPAGE BisTris gels with MOPS running buffer (Thermo-Fisher), followed by immunoblotting as described previously, ${ }^{34,36}$ using anti-flag (1:2000), anti-myc (1:1000), and anti-ha (1:2000) antibodies, as well as a secondary antibody (or antibodies). IB patterns were imaged and 
quantified using the Odyssey 9120 instrument (Li-Cor Biotechnologies), its software, and the manufacturer's manual. In some experiments, cells were grown in SC medium without an exposure to a nonglucose carbon source. All Tc/PRT chases in this study were repeated at least twice (often thrice), with results differing by $₫ 0 \%$.

\section{RT-qPCR.}

Wild-type (wt) and gid4A K. lactis strains were grown on YPD, YPE, or YPKA medium for $20 \mathrm{~h}$ at $30^{\circ} \mathrm{C}$. Cells were collected by centrifugation and stored at $-80{ }^{\circ} \mathrm{C}$ until RNA isolation. Total RNA was thereafter isolated using the Quick-RNA Fungal/Bacterial Miniprep Kit (Zymoresearch). Reverse-transcription reactions were carried out with samples containing $1 \mu \mathrm{g}$ of yeast RNA, the oligo-(dT) 18 primer, and NxGen M-MuLV reverse transcriptase (Lucigen). qPCR was then performed with the resulting cDNA samples as previously described, ${ }^{64,91}$ using $2 \times$ qPCR master mix without ROX (Bioland Scientific), the Mastercycler Ep Realplex (Eppendorf), and specific primers for the GID4, FBP1, and PCK1 genes of $K$. lactis. The pairs of primers were chosen to amplify $100 \mathrm{bp}$ gene-specific DNA fragments. The levels of TAF10 mRNA, encoding a subunit of the transcription initiation factor TFIID, were used for normalization/calibration of qPCR data. ${ }^{91}$ Detailed information about primers will be supplied upon request.

\section{Evaluating the in Vivo Efficiency of Translation Inhibitors.}

To the best of our knowledge, translation inhibitor-based chase-degradation assays were not performed previously with $K$. lactis, whose ribosomes are resistant to cycloheximide. ${ }^{80} \mathrm{We}$ used in vivo translation-inhibition assays to search for a translation inhibitor that could be used with $K$. lactis and chose blasticidin, as described in Results and Discussion. In evaluating the in vivo efficacy of translation inhibitors in $K$. lactis, we employed a version of the $\left[{ }^{35} \mathrm{~S}\right]$ methionine-based procedure that we described previously. ${ }^{40}$ A single colony of $K$. lactis was picked, and cells were grown in SD liquid medium at $30{ }^{\circ} \mathrm{C}$ overnight. The cell suspension was diluted with $\mathrm{SD}$ medium to an $\mathrm{OD}_{600}$ of $\sim 0.6$ and allowed to grow for an additional $2 \mathrm{~h} ; 0.5 \mathrm{~mL}$ of the cell suspension $\left(\mathrm{OD}_{600}=1\right)$ was gently pelleted, washed in fresh SD medium lacking Met, and resuspended in $0.5 \mathrm{~mL}$ of the same medium, followed by incubation at $30{ }^{\circ} \mathrm{C}$ for $40 \mathrm{~min}$. Thereafter, either a "control" volume of dimethyl sulfoxide (DMSO, the solvent for inhibitor stock solutions) or specific translation inhibitors (either cycloheximide, to a final concentration of $4 \mathrm{mg} / \mathrm{mL}$, or $\mathrm{G} 418$, to a final concentration of 4 $\mathrm{mg} / \mathrm{mL}$, or hygromycin- $\mathrm{B}$, to a final concentration of $4 \mathrm{mg} / \mathrm{mL}$, or blasticidin, to a final concentration from 0.01 to $0.5 \mathrm{mg} / \mathrm{mL}$ ) were added to a cell suspension in SD medium lacking Met, followed by incubation at $30^{\circ} \mathrm{C}$ for $20 \mathrm{~min}$ and a $10 \mathrm{~min}$ treatment (pulse labeling) with $\left[{ }^{35} \mathrm{~S}\right] \mathrm{Met} / \mathrm{Cys}$ (EasyTag-EXPRESS $-{ }^{35} \mathrm{~S}$, PerkinElmer), with cells in $0.5 \mathrm{~mL}$ of medium containing $40 \mu \mathrm{Ci}$ of $\left[{ }^{35} \mathrm{~S}\right] \mathrm{Met} / \mathrm{Cys}$. Cells in each sample were pelleted by centrifugation at $11200 \mathrm{~g}$ for $1 \mathrm{~min}$ and washed twice with SD medium. Each cell pellet was resuspended in $1 \mathrm{~mL}$ of $0.1 \mathrm{M} \mathrm{NaOH}$, followed by incubation for $5 \mathrm{~min}$ at room temperature. A cell suspension was centrifuged at $11200 \mathrm{~g}$ for $1 \mathrm{~min}$ and resuspended in 50 $\mu \mathrm{L}$ of buffer $\mathrm{HU}$ (see above), followed by incubation at $70{ }^{\circ} \mathrm{C}$ for $10 \mathrm{~min}$, SDS-PAGE, an electro-transfer to a membrane, and ${ }^{35} \mathrm{~S}$ autoradiography, using a Typhoon FLA 9500 scanner (GE Healthcare) and its cassettes. 


\section{RESULTS AND DISCUSSION}

\section{The N-Terminal Proline (Pro) of S. cerevisiae Fbp1, Mdh2, and Icl1 Is Absent in Their $K$. lactis Counterparts.}

The newly formed Fbp1 fructose-1,6-bisphosphatase of $S$. cerevisiae bears Nt-Pro, after cotranslational removal of the initially present Nt-Met residue by ribosome-associated Metaminopeptidases ${ }^{24,64,92}$ (Figure S2A). (A Met-aminopeptidase would efficaciously cleave off Nt-Met if a residue at position 2, to be made $\mathrm{N}$-terminal by the cleavage, is not larger than the Val residue. ${ }^{2,18}$ ) Examined genomes of other Saccharomyces yeasts also encode Fbp1 enzymes that bear Nt-Pro. In contrast, Fbp1 enzymes of many (though not all) non-Saccharomyces budding yeasts lack Nt-Pro. For example, although the sequence of $K$. lactis $\mathrm{Fbp} 1$ is $\sim 74 \%$ identical to that of $S$. cerevisiae Fbp1, K. lactis Fbp1 bears Nt-Ala (Figure S2A). Mdh2 and Icl1, the other gluconeogenic enzymes that also bear Nt-Pro in $S$. cerevisiae, contain, respectively and in contrast, Nt-Ser and Nt-Val in K. lactis (Figure S2AC). Mammalian counterparts of these enzymes also lack Nt-Pro.

The Pro residue at position 2 of the phosphoenolpyruvate carboxykinase Pck1 (Figure S2D), the fourth gluconeogenic enzyme, is required for its Gid4/GID-mediated degradation in $S$. cerevisiae. ${ }^{24}$ In contrast to Fbp1, Mdh2, and Icl1, the position 2 Pro residue of S. cerevisiae Pck1 is conserved not only in $K$. lactis Pck1 (Figure S2D) but also among fungi at large, and in most other phosphoenolpyruvate carboxykinases throughout eukaryotes. ${ }^{24}$

\section{Both $K$. lactis and S. cerevisiae Gid4 Recognize the N-Terminal Pro Residue of S. cerevisiae Fbp1.}

We have shown that $S$. cerevisiae Gid4 is the main recognition component of the Pro/Ndegron pathway (Figure S1C). ${ }^{24,64}$ Gid10, a functionally minor Gid4-like N-recognin of the same pathway, is expressed only during specific stresses. ${ }^{64}$ Both $S$. cerevisiae and human Gid4 recognize protein substrates in particular through their Nt-Pro residue or a Pro at position 2 , in the presence of also required adjoining sequence motifs. ${ }^{24,26} S$. cerevisiae Fbp1 bears Nt-Pro and is a conditionally short-lived physiological substrate of the Pro/Ndegron pathway. ${ }^{24}$ In contrast, $K$. lactis Fbp1 bears Nt-Ala (Figure S2A). The $S$. cerevisiae and $K$. lactis Gid4 N-recognins are $37 \%$ identical. This sequelogy, ${ }^{79}$ while significant, is much lower than the $74 \%$ level of identity between the sequences of the $S$. cerevisiae and $K$. lactis Fbp1 enzymes (Figure S2A).

The last common ancestor of $S$. cerevisiae and $K$. lactis lived roughly 150 mya. ${ }^{74-78}$ A priori, the substrate recognition specificity of $K$. lactis Gid4 might have changed, over evolutionary time scales, by "following" the altered (non-Pro) identities of Nt residues of $K$. lactis Fbp1, Ic11, and Mdh2 (Figure S2A-C). Alternatively, the specificity of K. lactis Gid4 may be similar to that of its $S$. cerevisiae counterpart, reflecting the presence of other (remaining to be identified), nongluconeogenic physiological substrates of Gid4 in both yeasts that bear a degradation-relevant Nt-Pro residue.

To address these questions, we determined whether $K$. lactis Gid4 can recognize the Nt-Pro residue of a protein that is known to be recognized by $S$. cerevisiae Gid4. As demonstrated previously, ${ }^{24}$ we used $S$. cerevisiae-based two-hybrid (Y2H) binding assays by Fields and 
colleagues, ${ }^{89,90,93}$ in which the positions of Y2H-specific moieties, called the activation domain (AD) and the DNA binding domain (DBD), were such that at least one member of a fusion pair contained the original, unobstructed N-terminus. K. lactis Gid4 was found to interact with the wild-type (wt), Nt-Pro-bearing $S$. cerevisiae $\mathbf{P}$-Fbp1 but did not interact with the otherwise identical S-Fbp1 mutant bearing Nt-Ser (Figure 1, rows 1-5). This specificity was indistinguishable from that of the $S$. cerevisiae Gid4 N-recognin (Figure 1, rows 1 and 2). We have previously shown that $S$. cerevisiae Gid4 also does not bind to AFbp1, T-Fbp1, C-Fbp1, V-Fbp1, and G-Fbp1 Nt mutants. ${ }^{24}$ In addition, K. lactis Gid4 did not bind to $K$. lactis Mdh2, whose Nt residue was Ser (in contrast to the Nt-Pro residue of $S$. cerevisiae Mdh2) (Figure S2B and Figure 1, row 6).

The sequelogous (51\% identical) S. cerevisiae and $K$. lactis Mdh2 enzymes (bearing Nt-Pro and Nt-Ser, respectively) differ, in addition, in the presence, in K. lactis Mdh2, of an 40residue Nt sequence that is absent in $S$. cerevisiae Mdh2 (Figure S2B). The first Pro residue of $K$. lactis $\mathrm{Mdh} 2$ occurs in the sequence $\mathrm{P}^{37} \mathrm{AVNA}$, which is preceded by the Met residue (Figure S2B). To verify the unlikely but formally not precluded possibility that the synthesis of at least some molecules of $K$. lactis Mdh2 might be initiated, in vivo, at that internal Met [followed by its cotranslational removal and exposure of the potentially Gid4 binding NtPro-Ala-Val-Asn-Ala (PAVNA) sequence], we asked, using Y2H, whether $K$. lactis Gid4 might interact with the derivative of $K$. lactis Mdh2 that starts with Nt-Pro at position 37 (Figure S2B).

The results were clearly negative (Figure 1, row 7), in contrast to the binding of $K$. lactis Gid4 to the Nt-Pro-bearing wt $S$. cerevisiae Fbp1 (Figure 1, row 3; compare with row 7). Thus, although $K$. lactis Gid4 can recognize Nt-Pro (Figure 1, row 3; compare with row 4), this binding, similar to the properties of $S$. cerevisiae and human Gid4 (Figure 1, rows 1 and $2),{ }^{24,25}$ requires, in addition, the presence of adjoining sequence motifs that are distinct from the AVNA sequence mentioned above.

\section{Levels of Endogenous K. lactis GID4, FBP1, and PCK1 mRNAs.}

Reverse-transcription quantitative PCR (RT-qPCR) assays ${ }^{94,95}$ were carried out with total $K$. lactis RNA (using TAF10, encoding a subunit of the transcription initiation factor TFIID, as a calibration control) to determine, for the first time, the relative levels of mRNAs encoding $K$. lactis Gid4, Fbp1, and Pck1 under different metabolic conditions (Figure S4). The levels of $K$. lactis GID4 mRNA were significant and within 2-fold of each other in media containing glucose versus nonfermentable carbon sources such as ethanol or acetate (Figure S4A). No GID4 mRNA could be detected in gid $4 \Delta K$. lactis, as would be expected (Figure S4A). Similarly to findings with $S$. cerevisiae, the levels of $K$. lactis FBP1 mRNA in either wt or gid $4 \Delta K$. lactis in a glucose-containing medium were $25-45 \%$ of those in a medium containing (nonfermentable) ethanol or acetate (Figure S4B). These results indicated a transcriptional upregulation of $\mathrm{Fbp} 1$, which is required for gluconeogenesis (together with Mdh2, Icl1, and Pck1) in cells that grow on a nonfermentable carbon source (Figure S4B). ${ }^{96}$ The K. lactis PCK1 mRNA, while nearly absent in the presence of glucose, was strongly (15-30-fold) induced upon replacements of glucose with ethanol or acetate (Figure S4C). The relative levels of the mRNAs mentioned above in $K$. lactis under gluconeogenesis 
versus glucose-replete conditions were not dissimilar to those described with $S$. cerevisiae (ref 24 and references therein).

\section{K. lactis Fbp1, Bearing Nt-Ala, Is Long-Lived in both S. cerevisiae and $K$. lactis.}

The endogenous Gid4 N-recognin of $S$. cerevisiae is expressed in glucose-containing media (Figure S4A). ${ }^{24,64}$ In both the cited studies ${ }^{24,64}$ and the work presented here, protein degradation was assayed using the promoter reference technique (PRT) (Figure 2A,B). ${ }^{40}$ In this tetracycline $(\mathrm{Tc})$-based method, a protein of interest and dihydrofolate reductase (DHFR, a long-lived reference protein) are expressed in S. cerevisiae from the same plasmid, from identical constitutive promoters that contain additional DNA elements. Once transcribed, these elements form $5^{\prime}$-RNA aptamers that can bind to added (cell-penetrating) Tc. As a result, the addition of Tc, which does not affect global translation in the yeast cytosol, can selectively repress translation of the aptamer-containing mRNAs that encode the reference protein and the test protein (Figure 2A,B). ${ }^{40}$ Advantages of Tc/PRT chasedegradation assays include the accuracy-increasing coexpression of a reference protein and the freedom to avoid the use of cytotoxic global translation inhibitors such as, for example, cycloheximide. ${ }^{97}$ Following the addition of Tc, a decrease, during a chase, in the amount of a test protein relative to the reference protein tracks degradation of the test protein. ${ }^{40}$

In contrast to the Nt-Pro-bearing (and therefore short-lived) $S$. cerevisiae P-Fbp1 ( $S c$-PFbp1), ${ }^{24,64}$ the Nt-Ala-bearing, C-terminally triple-flag-tagged $K$. lactis $\mathbf{A}-F b p 1_{3 f}$ (KI-A$\mathrm{Fbp}_{3 \mathrm{f}}$ ) was a long-lived protein in both wt $S$. cerevisiae and its gid $4 \Delta$ mutant (Figure 2D), in agreement with the Nt-Pro binding specificity of $S$. cerevisiae Gid4 (Figures 1 and 2). ${ }^{24}$ Synthesis of $S$. cerevisiae Gid4 is rapidly and strongly (but transiently) induced during medium shifts from (nonfermentable) ethanol to glucose. ${ }^{53,54}$ Therefore, Tc/PRT chasedegradation assays were also performed with $S$. cerevisiae cells that were incubated for $20 \mathrm{~h}$ in ethanol-containing medium at $30^{\circ} \mathrm{C}$ before being shifted to glucose-containing medium. The results were the same as those with glucose medium alone during an otherwise identical chase-degradation assay. In summary, $\mathrm{Kl}-\mathbf{A}-\mathrm{Fbp} 1_{3 \mathrm{f}}$ was long-lived in $\mathrm{S}$. cerevisiae (Figure 2C,D). Kl-A-Fbp $1_{3 \mathrm{f}}$ was long-lived in $K$. lactis as well (Figure 3A, lanes 2-5; see also below).

\section{Other Similarities and Differences among Gluconeo-genesis-Relevant Proteins of $\boldsymbol{S}$. cerevisiae and $K$. lactis.}

We have shown ${ }^{24}$ that $S$. cerevisiae Pck1 (Sc-SP-Pck1), the fourth gluconeogenic enzyme, is targeted for the Gid4/GID-mediated degradation that requires the position 2 Pro residue of Pck1. The position 2 Pro is conserved in Pck1 of $K$. lactis (Figure S2D) and many other eukaryotes. ${ }^{24}$ We found, however, using Tc/PRT assays with $S c$-SP-Pck $1_{3 \mathrm{f}}$ versus $\mathrm{Kl}$-SP$\mathrm{Pck}_{3 \mathrm{f}}$ that $\mathrm{Kl}$-SP-Pck $1_{3 \mathrm{f}}$ was long-lived in $S$. cerevisiae, in contrast to $S c$-SP-Pck $1_{3 \mathrm{f}}$ (Figure 2E,F). Because the detailed organization of the Gid4-dependent degron of Pck1 is not clearly understood even with $S$. cerevisiae Pck1 (Sc-SP-Pck1 $\left.1_{3 f}\right),{ }^{24}$ the observed difference between metabolic stabilities of $S$. cerevisiae and $K$. lactis Pck1 proteins (Figure $2 \mathrm{E}, \mathrm{F})$ would have to be addressed by future studies in this field. 
The S. cerevisiae Gid4 N-recognin, a subunit of the GID Ub ligase (Figure S1C), is a shortlived protein that is targeted for degradation to a large extent by GID itself (ref 24 and references therein). We found that the $\mathrm{N}$-terminally myc9-tagged $K$. lactis ${ }_{\operatorname{myc} 9} \mathrm{Gid}^{\mathrm{Kl}}$ is also short-lived in S. cerevisiae and is also targeted to a large extent by GID itself (Figure 2G). As neither of these Gid4 proteins bears Nt-Pro or a Pro at position 2, their GID-recognized degron(s) remains to be identified and mapped.

\section{A Blasticidin-Based Chase-Degradation Assay.}

The reference-based, Tc-based PRT chase-degradation assay is confined, at present, to $S$. cerevisiae and highly similar yeasts. ${ }^{24,40}$ Extending Tc/PRT assays to $K$. lactis is feasible but would be a project, given the necessity of $K$. lactis-specific alterations of the parental PRT plasmid and its promoters ${ }^{40}$ (see Materials and Methods), as well as optimization of a resulting (modified) Tc/PRT. In addition and independently, cycloheximide, a global translation inhibitor that is usually used in "standard" (not based on Tc) chase-degradation assays, cannot be employed with $K$. lactis, inasmuch as $K$. lactis ribosomes are resistant to cycloheximide $^{80}$ (we confirmed that finding).

Given these complications, we examined, with $K$. lactis cells, translation inhibitors other than cycloheximide, specifically G418 (Geneticin), hygromycin-B, and blasticidin. ${ }^{98}$ All three of them could inhibit protein synthesis in $K$. lactis. Blasticidin was a particularly efficacious translation inhibitor (Figure S3). K. lactis cells of an exponentially growing culture in SD medium were collected by centrifugation, resuspended in methionine-lacking $\mathrm{SD}[-\mathrm{Met}]$ medium, then washed and resuspended in the same medium (to the final $\mathrm{OD}_{600}$ of $\sim$ ), and incubated at $30^{\circ} \mathrm{C}$ for $40 \mathrm{~min}$, followed by the addition of blasticidin to varying final concentrations $(0.01,0.025,01,0.3$, and $0.5 \mathrm{mg} / \mathrm{mL})$ and a further incubation for 20 min. A 10 min "pulse" with $\left[{ }^{35} \mathrm{~S}\right] \mathrm{Met} / \mathrm{Cys}$ (in the presence of the indicated levels of blasticidin) was then performed, followed by preparation of whole-cell extracts, SDSPAGE, and ${ }^{35} \mathrm{~S}$ autoradiography (see Materials and Methods). Under these conditions, the addition of blasticidin to the level of $0.1 \mathrm{mg} / \mathrm{mL}$ inhibited translation in $K$. lactis nearly completely (>95\%) (Figure S3, lanes 4 in panels A and B; compare with lanes 1). Given these results, we carried out $K$. lactis chase-degradation assays with blasticidin at 0.1 $\mathrm{mg} / \mathrm{mL}$, as described below.

All strains of $K$. lactis used in this work were derived from the Dombrowski van der Walt strain, obtained from the American Type Culture Collection (ATCC) (see Materials and Methods). These strains exhibited properties characteristic of $K$. lactis, which were different from those of $S$. cerevisiae. For example, our $K$. lactis strains reached at least 2 -fold higher stationary cell densities in a rich (YPD) medium than did $S$. cerevisiae. In addition, our $K$. lactis strains required much longer spans of flanking region nucleotide sequence identities for site-specific mutagenesis in vivo (hundreds of DNA base pairs with $K$. lactis, i.e., an order of magnitude longer flanking DNA regions than analogous constructs with $S$. cerevisiae) (see Materials and Methods). Nevertheless, and in part because $S$. cerevisiae and $K$. lactis yeasts looked similar under a light microscope, we also performed, with our $K$. lactis strains, PCR-based direct verifications of $K$. lactis identity. These tests eliminated the 
unlikely but formally not precluded possibility of an inadvertent replacement of $K$. lactis with S. cerevisiae in our experiments (Figure S5).

\section{Replacing the N-Terminal AGIK Sequence of $K$. lactis Fbp1 with the N-Terminal PTLV Sequence of $S$. cerevisiae Fbp1 Makes the Resulting ptlv-Fbp1 Short-Lived in K. lactis.}

The Nt sequence of wt $K$. lactis Fbp1 (after the cotranslational removal of Nt-Met) is AlaGly-Ile-Lys (AGIK). Both $S$. cerevisiae and human Gid4 N-recognins of the Pro/N-degron pathway (Figure S1C) target Pro/N-degrons by recognizing the first approximately four Nt residues of a substrate protein, with an emphasis on the first and second residues. ${ }^{24-26} \mathrm{We}$ asked, therefore, whether a replacement of the first four Nt residues (AGIK) of $K$. lactis Fbp1 with the first four Nt residues (PTLV) of $S$. cerevisiae Fbp1 (the latter is short-lived in $S$. cerevisiae ${ }^{24,64}$ ) might confer a short half-life, in $K$. lactis, on the resulting "chimeric" $K$. lactis Fbp1 derivative, which would be identical to $K$. lactis Fbp1 save for its first four residues. We also asked whether this degradation (if it could occur in the first place) would require $K$. lactis Gid4. The derivative of $K$. lactis Fbp1 mentioned above was denoted as ptlv- $K l-F b p 1_{3 h a}$, with the Nt sequence "ptlv" in lowercase, to avoid confusion vis-à-vis an uppercase letter in the rest of protein's name.

To make these experiments possible, the chromosomal $K$. lactis FBP1 gene was modified, using reverse genetics in $K$. lactis (see Materials and Methods), by extending the FBP1 open reading frame (ORF) with a sequence encoding the $\mathrm{C}$-terminal triple-ha tag. In the second step, the Nt-MAGIK-coding sequence of the otherwise wt chromosomal K. lactis FBP1 3 ha gene was replaced with the Nt-MPTLV-coding sequence. The resulting chromosomal ORF encoded ptlv- $K l-F b p 1_{3 \text { ha }}$, which was expressed from the endogenous $K$. lactis FBP1 locus and the $K$. lactis $\mathrm{P}_{F B P 1}$ promoter.

In one set of chase-degradation assays, a K. lactis culture was grown, for $20 \mathrm{~h}$, in ethanolbased minimal medium, followed by washing of cells with glucose-based medium and their further incubation in that medium. Chase-degradation assays were initiated 3 min after the transfer of $K$. lactis cells from ethanol to glucose. In other words, time-zero points, in the data of Figure 3A, were sampled 3 min after resuspension of $K$. lactis cells in glucose medium. These assays (save for one; see below) involved the halting of translation through the addition of blasticidin at the beginning of chase (see above, Figure S3, and Materials and Methods). The measurements involved SDS-PAGE of whole-cell extracts and immunoblotting with the anti-ha antibody to detect either wt $K$. lactis Fbp1 (denoted as agik$K l-F b p 1_{3 h a}$ ) or its derivative (expressed from the same genomic locus) ptlv- Kl-Fbp $1_{3 \text { ha }}$ (Figure 3A, lanes 2-9).

As would be expected, given the $\mathrm{Nt}-\mathrm{Ala}$ residue of wt $K$. lactis agik- $K l-\mathrm{Fbp} 1_{3 \text { ha }}$, this protein was stable over at least $2 \mathrm{~h}$ of chase in $K$. lactis (Figure 3A, lanes 2-5). In strong contrast, the otherwise identical ptlv-Kl-Fbp1 3 ha, bearing, instead of Nt-AGIK, the Nt-PTLV sequence of $S$. cerevisiae Fbp1 (which is short-lived in $S$. cerevisiae ${ }^{24,64}$ ), was highly unstable in $K$. lactis. Specifically, there was much less ptlv-Kl-Fbp1 3 ha (in comparison to agik-Kl-Fbp $1_{3 \mathrm{ha}}$ ) at the beginning of chase (time-zero point). Moreover, the intensity of the band of ptlv-Kl-Fbp1 3 ha decreased to nearly undetectable levels by $30 \mathrm{~min}$ of chase (Figure $3 \mathrm{~A}$, lanes 6-9; compare with lanes 2-5). This degradation of ptlv- Kl-Fbp1 3 ha required Gid4 
(and, by inference, the rest of the GID Ub ligase), as ptlv- Kl-Fbp $1_{3 \mathrm{ha}}$ became long-lived in a congenic gid4A K. lactis mutant (Figure 3A, lanes 10-13; compare with lanes 6-9).

Interestingly, we discovered that omitting blasticidin, a global translation inhibitor used in our K. lactis chase-degradation assays (Figure S3), did not significantly alter the observed in vivo degradation of ptlv- $K l$-Fbp $1_{3 \text { ha }}$ under the assay's temporal conditions (specifically, the transfer of cells from ethanol to glucose). The intensity of the band of ptlv-Kl-Fbp $1_{3 \text { ha }}$ rapidly decreased (nearly disappearing by $30 \mathrm{~min}$ ) upon the transition from ethanol-based medium to a glucose-based one even in the absence of blasticidin (Figure 3A, lanes 14-17; compare with lanes 6-9). In addition to demonstrating a short half-life of ptlv- Kl-Fbp1 ${ }_{3 \mathrm{ha}}$ in $K$. lactis during the transition from ethanol to glucose, these results also indicated that the rate of synthesis of ptlv-Kl-Fbp $1_{3 \text { ha }}$ was either low or negligible during the transition described above, thereby making it possible to detect the degradation of ptlv- Kl-Fbp $1_{3 \text { ha }}$. Note that ptlv- Kl-Fbp1 3 ha must have been synthesized and was likely to be relatively stable before the ethanol-to-glucose transition [as happens to be the case with $S$. cerevisiae Fbp1 in S. cerevisiae, ${ }^{50,54,56,58}$ because the enzymatic activity of Fbp 1 (ptlv- $K l$-Fbp $1_{3 \mathrm{ha}}$ ) is required for gluconeogenesis-mediated glucose production during growth on ethanol].

The results of blasticidin-based chase-degradation assays with ptlv- Kl-Fbp $1_{3 \mathrm{ha}}$ in the continuous presence of glucose (i.e., in the absence of ethanol-to-glucose transition) were largely similar to the results described above (Figure 3B; compare with Figure 3A). The only significant difference was a lower rate of degradation of "residual" amounts of ptlv- $K \mathrm{~K}$ $\mathrm{Fbp}_{3 \mathrm{ha}}$ that were still retained, during a chase-degradation assay, after the beginning of the chase (time zero) (Figure 3B, lanes 6-9; compare with Figure 3A, lanes 6-9). A plausible explanation of this effect is that Gid4, the N-recognin of the Pro/N-degron pathway, is a longer-lived protein during the ethanol-to-glucose transition (in agreement with findings about the $S$. cerevisiae Gid4 N-recognin ${ }^{54}$ ), than in a glucose-alone medium, in which Gid4 would be a shorter-lived protein. If so, the immediate cessation of Gid4 synthesis upon the addition of blasticidin in a glucose medium would rapidly curtail [owing to the instability of Gid4 in glucose alone (see below)] the Gid4/GID-dependent degradation of ptlv- Kl-Fbp $1_{3 \text { ha }}$ during a blasticidin-based chase in glucose, in comparison to the setting of a blasticidin-free transition from ethanol to glucose, when $K$. lactis Gid4 is likely to be significantly longerlived (similar to the $S$. cerevisiae Gid4 N-recognin ${ }^{54,61}$ ).

\section{CONCLUDING REMARKS}

S. cerevisiae and $K$. lactis diverged roughly 150 mya. ${ }^{74-76}$ To the best of our knowledge, this work (Figures 1-3 and Figures S1-S5) is the first study of the Ub system in K. lactis. It is also the first comparison of Pro/N-degron pathways in two diverged budding yeasts. In addition, we developed the first (blasticidin-based) chase-degradation assay suitable for use with $K$. lactis, because the ribosomes of this organism, in contrast to ribosomes of most other eukaryotes, are resistant to cycloheximide. ${ }^{80}$

One evolutionary question that has been addressed and answered in this study was whether the difference between the Nt-Pro residues of the $S$. cerevisiae Fbp1, Icl1, and Mdh2 gluconeogenic enzymes and non-Pro Nt-residues in the $K$. lactis counterparts of these 
enzymes (Figure S2) was "accompanied", over evolutionary time scales, by a significant change in the recognition specificity of the Gid4 N-recognin. (In S. cerevisiae, Gid4 targets Nt-Pro in the presence of nonrandom adjoining sequence motifs.) The clear answer was that the recognition specificity of $K$. lactis Gid4 was indistinguishable, in the context of $\mathrm{Y} 2 \mathrm{H}$ assays, from that of $S$. cerevisiae Gid4 (Figure 1). Continuing this line of inquiry, we showed that the non-Pro (Ala) Nt residue of $K$. lactis Fbp1 made this enzyme long-lived in $K$. lactis. In addition, we also found that the replacement of Nt-Ala and the next three residues of $K$. lactis Fbp1 with the four-residue Nt-PTLV sequence of $S$. cerevisiae Fbp1 was sufficient for the resulting "hybrid" (largely K. lactis) Fbp1 to become a short-lived substrate of Gid4 in K. lactis (Figure 3).

A parsimonious interpretation of these results is that $K$. lactis Gid4 targets for degradation other, currently unknown $K$. lactis proteins that bear Nt-Pro, in addition to proteins that bear other sequence motifs, including a Pro at position 2, as in the Pck1 gluconeogenic enzyme of $S$. cerevisiae and K. lactis. S. cerevisiae and K. lactis DNA encode $\sim 300$ and $\sim 220$ proteins, respectively, that bear Nt-Pro (after the cotranslational removal of the initially present NtMet). Our previous work with $S$. cerevisiae proteins (other than gluconeogenic enzymes) that naturally bear Nt-Pro illustrated the complexity of substrate recognition and ubiquitylation by Gid4 and the rest of GID, in that the binding by the $S$. cerevisiae Gid4 required not only Nt-Pro but also adjoining sequence motifs. ${ }^{24}$ In addition, binding was (in a few cases examined so far) not always sufficient for protein degradation, presumably owing to a suboptimal GID-mediated polyubiquitylation of some Gid4-bound proteins. ${ }^{24} \mathrm{An}$ analogous disposition is likely to recur in a future search for Nt-Pro-bearing physiological substrates of the $K$. lactis Pro/N-degron pathway.

A quasi-random genetic drift can result, occasionally, in fixation not only of neutral alterations of protein-coding DNA sequences but also of mildly deleterious alleles as well. The probability of such (unselected for) fixation is higher among eukaryotes, with their relatively low effective population sizes, in comparison to those of bacteria. ${ }^{99}$ In summary, a genetic drift was likely the chief cause of (metabolically stabilizing) non-Pro Nt residues in $K$. lactis gluconeogenic enzymes. In contrast, the apparently unaltered substrate specificity of $K$. lactis Gid4 relative to $S$. cerevisiae Gid4 (Figure 1) strongly suggested the presence of selection pressures that precluded an analogous alteration of the Gid4 N-recognin, owing, most likely, to other, additional and currently unknown nongluconeogenic physiological substrates of Gid4 in both of these budding yeasts. Because the N-termini of mammalian non-Pck1 gluconeogenic enzymes are also distinct from their $S$. cerevisiae counterparts, it would be informative to extend evolutionary analyses of this study to analogous comparisons between yeast and mammalian Pro/N-degron pathways.

\section{Supplementary Material}

Refer to Web version on PubMed Central for supplementary material.

\section{ACKNOWLEDGMENTS}

The authors thank current and former members of the Varshavsky laboratory for their advice and assistance. 
Funding

This work was supported by National Institutes of Health Grants 1R01GM031530 and 1R01DK039520 (A.V.).

\section{ABBREVIATIONS}

$\begin{array}{ll}\text { CHX } & \text { cycloheximide } \\ \text { DUB } & \text { deubiquitylase } \\ \text { IB } & \text { immunoblotting } \\ \text { mya } & \text { million years ago } \\ \text { ORF } & \text { open reading frame } \\ \text { PRT } & \text { promoter reference technique } \\ \text { RT-qPCR } & \text { reverse-transcription/quantitative polymerase chain reaction } \\ \text { SDS-PAGE } & \text { sodium dodecyl sulfate-polyacrylamide gel electrophoresis } \\ \text { Tc } & \text { tetracycline } \\ \text { Ub } & \text { ubiquitin } \\ \text { UPS } & \text { ubiquitin-proteasome system } \\ \text { wt } & \text { wild-type } \\ \text { Y2H } & \text { yeast-based two-hybrid }\end{array}$

\section{REFERENCES}

(1). Hershko A, Ciechanover A, and Varshavsky A (2000) The ubiquitin system. Nat. Med 6, 10731081. [PubMed: 11017125]

(2). Varshavsky A (2019) N-degron and C-degron pathways of protein degradation. Proc. Natl. Acad. Sci. U. S. A 116, 358-366. [PubMed: 30622213]

(3). Finley D, Ulrich HD, Sommer T, and Kaiser P (2012) The ubiquitin-proteasome system of Saccharomyces cerevisiae. Genetics 192, 319-360. [PubMed: 23028185]

(4). Vittal V, Stewart MD, Brzovic PS, and Klevit RE (2015) Regulating the regulators: recent revelations in the control of E3 ubiquitin ligases. J. Biol. Chem 290, 21244-21251. [PubMed: 26187467]

(5). Grumati P, and Dikic I (2018) Ubiquitin signaling and autophagy. J. Biol. Chem 293, 5404-5413. [PubMed: 29187595]

(6). Ji CH, and Kwon YT (2017) Crosstalk and interplay between the ubiquitin-proteasome system and autophagy. Mol. Cells 40, 441-449. [PubMed: 28743182]

(7). Balchin D, Hayer-Hartl M, and Hartl FU (2016) In vivo aspects of protein folding and quality control. Science 353, aac4354. [PubMed: 27365453]

(8). Zheng N, and Shabek N (2017) Ubiquitin ligases: structure, function, and regulation. Annu. Rev. Biochem 86, 129-157. [PubMed: 28375744]

(9). Watson ER, Brown NG, Peters JM, Stark H, and Schulman BA (2019) Posing the APC/C E3 ubiquitin ligase to orchestrate cell division. Trends Cell Biol 29, 117-134. [PubMed: 30482618]

(10). Bard JAM, Goodall EA, Greene ER, Jonsson E, Dong KC, and Martin A (2018) Structure and function of the 26S proteasome. Annu. Rev. Biochem 87, 697-724. [PubMed: 29652515] 
(11). Schweitzer A, Aufderheide A, Rudack T, Beck F, Pfeifer G, Plitzko JM, Sakata E, Schulten K, Forster F, and Baumeister W (2016) Structure of the human 26S proteasome at a resolution of 3.9 A. Proc. Natl. Acad. Sci. U. S. A 113, 7816-7821. [PubMed: 27342858]

(12). Finley D, Chen X, and Walters KJ (2016) Gates, channels, and switches: elements of the proteasome machine. Trends Biochem. Sci 41, 77-93. [PubMed: 26643069]

(13). Collins GA, and Goldberg AL (2017) The logic of the 26 S proteasome. Cell 169, 792-806. [PubMed: 28525752]

(14). Budenholzer L, Cheng CL, Li Y, and Hochstrasser M (2017) Proteasome structure and assembly. J. Mol. Biol 429, 3500-3524. [PubMed: 28583440]

(15). Yu H, and Matouschek A (2017) Recognition of client proteins by the proteasome. Annu. Rev. Biophys 46, 149-173. [PubMed: 28301771]

(16). Bachmair A, Finley D, and Varshavsky A (1986) In vivo half-life of a protein is a function of its amino-terminal residue. Science 234, 179-186. [PubMed: 3018930]

(17). Bachmair A, and Varshavsky A (1989) The degradation signal in a short-lived protein. Cell 56, 1019-1032. [PubMed: 2538246]

(18). Varshavsky A (2011) The N-end rule pathway and regulation by proteolysis. Protein Sci 20, 1298-1345. [PubMed: 21633985]

(19). Dougan DA, Micevski D, and Truscott KN (2012) The N-end rule pathway: from recognition by $\mathrm{N}$-recognins to destruction by AAA+ proteases. Biochim. Biophys. Acta, Mol. Cell Res 1823, 83-91.

(20). Tasaki TS, Sriram SM, Park KS, and Kwon YT (2012) The N-end rule pathway. Annu. Rev. Biochem 81, 261-289. [PubMed: 22524314]

(21). Aksnes H, Drazic A, Marie M, and Arnesen T (2016) First things first: vital protein marks by Nterminal acetyltransferases. Trends Biochem. Sci 41, 746-760. [PubMed: 27498224]

(22). Gibbs DJ, Bacardit J, Bachmair A, and Holdsworth MJ (2014) The eukaryotic N-end rule pathway: conserved mechanisms and diverse functions. Trends Cell Biol. 24, 603-611. [PubMed: 24874449]

(23). Dissmeyer N, Rivas S, and Graciet E (2018) Life and death of proteins after protease cleavage: protein degradation by the N-end rule pathway. New Phytol. 218, 929-935. [PubMed: 28581033]

(24). Chen SJ, Wu X, Wadas B, Oh J-H, and Varshavsky A (2017) An N-end rule pathway that recognizes proline and destroys gluconeogenic enzymes. Science 355, eaal3655. [PubMed: 28126757]

(25). Dong C, Zhang H, Li L, Tempel W, Loppnau P, and Min J (2018) Molecular basis of GIDmediated recognition of degrons for the Pro/N-end rule pathway. Nat. Chem. Biol 14, 466-473. [PubMed: 29632410]

(26). Dougan DA, and Varshavsky A (2018) Understanding the Pro/N-end rule pathway. Nat. Chem. Biol 14, 415-416. [PubMed: 29662186]

(27). Kim JM, Seok OH, Ju S, Heo JE, Yeom J, Kim DS, Yoo JY, Varshavsky A, Lee C, and Hwang CS (2018) Formyl-methionine as an N-degron of a eukaryotic N-end rule pathway. Science 362, eaat0174. [PubMed: 30409808]

(28). Hwang CS, Shemorry A, and Varshavsky A (2010) N-terminal acetylation of cellular proteins creates specific degradation signals. Science 327, 973-977. [PubMed: 20110468]

(29). Piatkov KI, Brower CS, and Varshavsky A (2012) The N-end rule pathway counteracts cell death by destroying proapoptotic protein fragments. Proc. Natl. Acad. Sci. U. S. A 109, E1839-E1847. [PubMed: 22670058]

(30). Brower CS, Piatkov KI, and Varshavsky A (2013) Neurodegeneration-associated protein fragments as short-lived substrates of the N-end rule pathway. Mol. Cell 50, 161-171. [PubMed: 23499006]

(31). Kasu YAT, Alemu S, Lamari A, Loew N, and Brower CS (2018) The N-termini of TAR DNAbinding protein 43 (TDP43) C-terminal fragments influence degradation, aggregation propensity, and morphology. Mol. Cell. Biol 38, e00243-00218. [PubMed: 29987190]

(32). Kim HK, Kim RR, Oh JH, Cho H, Varshavsky A, and Hwang CS (2014) The N-terminal methionine of cellular proteins as a degradation signal. Cell 156, 158-169. [PubMed: 24361105] 
(33). Nguyen KT, Lee C-S, Mun S-H, Truong NT, Park SK, and Hwang C-S (2019) N-terminal acetylation and $\mathrm{N}$-end rule pathway control degradation of the lipid droplet protein PLIN2. J. Biol. Chem 294, 379-388. [PubMed: 30425097]

(34). Shemorry A, Hwang CS, and Varshavsky A (2013) Control of protein quality and stoichiometries by N-terminal acetylation and the N-end rule pathway. Mol. Cell 50, 540-551. [PubMed: 23603116]

(35). Shearer RF, Iconomou M, Watts CK, and Saunders DN (2015) Functional roles of the E3 ubiquitin ligase UBR5 in cancer. Mol. Cancer Res 13, 1523-1532. [PubMed: 26464214]

(36). Oh JH, Hyun JY, and Varshavsky A (2017) Control of Hsp90 chaperone and its clients by Nterminal acetylation and the N-end rule pathway. Proc. Natl. Acad. Sci. U. S. A 114, E4370E4379. [PubMed: 28515311]

(37). Rivera-Rivera I, Román-Hernández G, Sauer RT, and Baker TA (2014) Remodeling of a delivery complex allows ClpS-mediated degradation of N-degron substrates. Proc. Natl. Acad. Sci. U. S. A 111, E3853-E3859. [PubMed: 25187555]

(38). Yoo YD, Mun SR, Ji CH, Sung KW, Kang KY, Heo AJ, Lee SH, An JY, Hwang J, Xie XQ, Ciechanover A, Kim BY, and Kwon YT (2018) N-terminal arginylation generates a bimodal degron that modulates autophagic proteolysis. Proc. Natl. Acad. Sci. U. S. A 115, E2716-E2724. [PubMed: 29507222]

(39). Vicente J, Mendiondo GM, Pauwels J, Pastor V, Izquierdo Y, Naumann C, Movahedi M, Rooney D, Gibbs DJ, Smart K, Bachmair A, Gray JE, Dissmeyer N, Castresana C, Ray RV, Gevaert K, and Holdsworth MJ (2019) Distinct branches of the N-end rule pathway modulate the plant immune response. New Phytol. 221, 988-1000. [PubMed: 30117535]

(40). Oh JH, Chen SJ, and Varshavsky A (2017) A reference-based protein degradation assay without global translation inhibitors. J. Biol. Chem 292, 21457-21465. [PubMed: 29122887]

(41). Masson N, Keeley TP, Giuntoli B, White MD, Puerta ML, Perata P, Hopkinson RJ, Flashman E, Licausi F, and Ratcliffe PJ (2019) Conserved N-terminal cysteine dioxygenases transduce responses to hypoxia in animals and plants. Science 365, 65-69. [PubMed: 31273118]

(42). Gao X, Yeom J, and Groisman EA (2019) The expanded specificity and physiological role of a widespread N-degron recognin. Proc. Natl. Acad. Sci. U. S. A 116, 18629-18637. [PubMed: 31451664]

(43). Timms RT, Zhang Z, Rhee DY, Harper JW, Koren I, and Elledge SJ (2019) A glycine-specific Ndegron pathway mediates the quality control of protein N-myristoylation. Science 365 , eaaw4912. [PubMed: 31273098]

(44). Inobe T, Fishbain S, Prakash S, and Matouschek A (2011) Defining the geometry of the twocomponent proteasome degron. Nat. Chem. Biol 7, 161-167. [PubMed: 21278740]

(45). Piatkov KI, Oh J-H, Liu Y, and Varshavsky A (2014) Calpain-generated natural protein fragments as short-lived substrates of the N-end rule pathway. Proc. Natl. Acad. Sci. U. S. A 111, E817E826. [PubMed: 24550490]

(46). Xu Z, Payoe R, and Fahlman RP (2012) The C-terminal proteolytic fragment of the breast cancer susceptibility type 1 protein (BRCA1) is degraded by the N-end rule pathway. J. Biol. Chem 287, 7495-7502. [PubMed: 22262859]

(47). Piatkov KI, Colnaghi L, Bekes M, Varshavsky A, and Huang TT (2012) The auto-generated fragment of the Usp1 deubiquitylase is a physiological substrate of the N-end rule pathway. Mol. Cell 48, 926-933. [PubMed: 23159736]

(48). Braun B, Pfirrmann T, Menssen R, Hofmann K, Scheel H, and Wolf DH (2011) Gid9, a second RING finger protein contributes to the ubiquitin ligase activity of the Gid complex required for catabolite degradation. FEBS Lett 585, 3856-3861. [PubMed: 22044534]

(49). Brown CR, Wolfe AB, Cui D, and Chiang HL (2008) The vacuolar import and degradation pathway merges with the endocytic pathway to deliver fructose-1,6-bisphosphatase to the vacuole for degradation. J. Biol. Chem 283, 26116-26127. [PubMed: 18660504]

(50). Hung G-C, Brown CR, Wolfe AB, Liu J, and Chiang H-L (2004) Degradation of the gluconeogenic enzymes fructose-1,6-bisphosphatase and malate dehydrogenase is mediated by distinct proteolytic pathways and signaling events. J. Biol. Chem 279, 49138-49150. [PubMed: 15358789] 
(51). Juretschke J, Menssen R, Sickmann A, and Wolf DH (2010) The Hsp70 chaperone Ssa1 is essential for catabolite induced degradation of the gluconeogenic enzyme fructose-1,6bisphosphatase. Biochem. Biophys. Res. Commun 397, 447-452. [PubMed: 20513352]

(52). Menssen R, Schweiggert J, Schreiner J, Kusevic D, Reuther J, Braun B, and Wolf DH (2012) Exploring the topology of the Gid complex, the E3 ubiquitin ligase involved in cataboliteinduced degradation of gluconeogenic enzymes. J. Biol. Chem 287, 25602-25614. [PubMed: 22645139]

(53). Regelmann J, Schule T, Josupeit FS, Horak J, Rose M, Entian KD, Thumm M, and Wolf DH (2003) Catabolite degradation of fructose-1,6-bisphosphatase in the yeast Saccharomyces cerevisiae: a genome-wide screen identifies eight novel GID genes and indicates the existence of two degradation pathways. Mol. Biol. Cell 14, 1652-1663. [PubMed: 12686616]

(54). Santt O, Pfirrmann T, Braun B, Juretschke J, Kimmig P, Scheel H, Hofmann K, Thumm M, and Wolf DH (2008) The yeast GID complex, a novel ubiquitin ligase (E3) involved in the regulation of carbohydrate metabolism. Mol. Biol. Cell 19, 3323-3333. [PubMed: 18508925]

(55). Schule T, Rose M, Entian KD, Thumm M, and Wolf DH (2000) Ubc8p functions in catabolite degradation of fructose-1, 6-bisphosphatase in yeast. EMBO J. 19, 2161-2167. [PubMed: 10811607]

(56). Alibhoy AA, and Chiang HL (2011) Vacuole import and degradation pathway: Insights into a specialized autophagy pathway. World J. Biol. Chem 2, 239-245. [PubMed: 22125667]

(57). Alibhoy AA, Giardina BJ, Dunton DD, and Chiang HL (2012) Vps34p is required for the decline of extracellular fructose-1,6-bisphosphatase in the vacuole import and degradation pathway. J. Biol. Chem 287, 33080-33093. [PubMed: 22833678]

(58). Giardina BJ, Stanley BA, and Chiang HL (2012) Comparative proteomic analysis of transition of saccharomyces cerevisiae from glucose-deficient medium to glucose-rich medium. Proteome Sci. 10, 40. [PubMed: 22691627]

(59). Hoffman M, and Chiang HL (1996) Isolation of degradation-deficient mutants defective in the targeting of fructose-1,6-bisphosphatase into the vacuole for degradation in Saccharomyces cerevisiae. Genetics 143, 1555-1566. [PubMed: 8844145]

(60). Liu H, and Pfirrmann T (2019) The Gid-complex: an emerging player in the ubiquitin ligase league. Biol. Chem 400, 1429. [PubMed: 30893051]

(61). Menssen R, Bui K, and Wolf DH (2018) Regulation of the Gid ubiquitin ligase recognition subunit Gid4. FEBS Lett 592, 3286-3294. [PubMed: 30136317]

(62). Giardina BJ, and Chiang HL (2013) Fructose-1,6-bisphosphatase, malate dehydrogenase, isocitrate lyase, phosphoenol-pyruvate carboxykinase, glyceraldehyde-3-phosphate dehydrogenase, and cyclophilin A are secreted in Saccharomyces cerevisiae grown in low glucose. Commun. Integr. Biol 6, No. e27216. [PubMed: 24563717]

(63). Chiang MC, and Chiang HL (1998) Vid24p, a novel protein localized to the fructose-1, 6bisphosphatase-containing vesicles, regulates targeting of fructose-1,6-bisphosphatase from the vesicles to the vacuole for degradation. J. Cell Biol 140, 1347-1356. [PubMed: 9508768]

(64). Melnykov A, Chen SJ, and Varshavsky A (2019) Gid10 as an alternative N-recognin of the Pro/N-degron pathway. Proc. Natl. Acad. Sci. U. S. A 116, 15914-15923. [PubMed: 31337681]

(65). Kobayashi N, Yang J, Ueda A, Suzuki T, Tomaru K, Takeno M, Okuda K, and Ishigatsubo Y (2007) RanBPM, muskelin, p48EMLP, p44CTLH, and the armadillo-repeat proteins ARMC8alpha and ARMC8beta are components of the CTLH complex. Gene 396, 236-247. [PubMed: 17467196]

(66). Francis O, Han F, and Adams JC (2013) Molecular phylogeny of a RING E3 ubiquitin ligase, conserved in eukaryotic cells and dominated by homologous components, the muskelin/ RanBPM/CTLH complex. PLoS One 8, No. e75217. [PubMed: 24143168]

(67). Pfirrmann T, Villavicencio-Lorini P, Subudhi AK, Menssen R, Wolf DH, and Hollemann T (2015) RMND5 from Xenopus laevis is an E3 ubiquitin-ligase and functions in early embryonic forebrain development. PLoS One 10, No. e0120342. [PubMed: 25793641]

(68). Lampert F, Stafa D, Goga A, Soste MV, Gilberto S, Olieric N, Picotti P, Stoffel M, and Peter M (2018) The multi-subunit GID/CTLH E3 ligase promotes proliferation and targets the transcription factor Hbp1 for degradation. eLife 7, No. e35528. [PubMed: 29911972] 
(69). Chang Y, Paramasivam M, Girgenti MJ, Walikonis RS, Bianchi E, and LoTurco JJ (2009) RanBPM regulates the progression of neuronal precursors through M-phase at the surface of the neocortical ventricular zone. Dev. Neurobiol 70, 1-15.

(70). Jin X, Pan Y, Wang L, Zhang L, Ravichandran R, Potts PR, Jiang J, Wu H, and Huang H (2017) MAGE-TRIM28 complex promotes the Warburg effect and hepatocellular carcinoma progression by targeting FBP1 for degradation. Oncogenesis 6, e312. [PubMed: 28394358]

(71). Leal-Esteban LC, Rothe B, Fortier S, Isenschmid M, and Constam DB (2018) Role of Bicaudal $\mathrm{C} 1$ in renal gluconeogenesis and its novel interaction with the CTLH complex. PLoS Genet. 14, No. e1007487. [PubMed: 29995892]

(72). Maitland MER, Onea G, Chiasson CA, Wang X, Ma J, Moor SE, Barber KR, Lajoie GA, Shaw GS, and Schild-Poulter C (2019) The mammalian CTLH complex is an E3 ubiquitin ligase that targets its subunit muskelin for degradation. Sci. Rep 9, 9864. [PubMed: 31285494]

(73). McTavish CJ, Berube-Janzen W, Wang X, Maitland MER, Salemi LM, Hess DA, and SchildPoulter C (2019) Regulation of c-Raf stability through the CTLH complex. Int. J. Mol. Sci 20, E934. [PubMed: 30795516]

(74). Rolland T, and Dujon B (2011) Yeasty clocks: dating genomic changes in yeasts. C. R. Biol 334, 620-628. [PubMed: 21819943]

(75). Dujon B (2010) Yeast evolutionary genomics. Nat. Rev. Genet 11, 512-524. [PubMed: 20559329]

(76). Marcet-Houben M, and Gabaldón T (2015) Beyond the whole-genome duplication: phylogenetic evidence for an ancient interspecies hybridization in the baker's yeast lineage. PLoS Biol. 13, No. e1002220. [PubMed: 26252497]

(77). Kellis M, Birren BW, and Lander ES (2004) Proof and evolutionary analysis of ancient genome duplication in the yeast Saccharomyces cerevisiae. Nature 428, 617-624. [PubMed: 15004568]

(78). Wolfe KH (2015) Origin of the yeast whole-genome puplication. PLoS Biol. 13, No. e1002221. [PubMed: 26252643]

(79). Varshavsky A (2004) Spalog and sequelog: neutral terms for spatial and sequence similarity. Curr. Biol 14, R181-R183. [PubMed: 15028230]

(80). Dehoux P, Davies J, and Cannon M (1993) Natural cycloheximide resistance in yeast. The role of ribosomal protein L41. Eur. J. Biochem 213, 841-848. [PubMed: 8477753]

(81). Ausubel FM, Brent R, Kingston RE, Moore DD, Smith JA, Seidman JG, and Struhl K (2017) Current Protocols in Molecular Biology, Wiley-Interscience, New York.

(82). Andrews B, Boone C, Davis TN, and Fields S (2016) Budding Yeast (a laboratory manual), Cold Spring Harbor Laboratory Press, Plainview, NY.

(83). Sanchenz M, Iglesias FJ, Santamaria C, and Dominguez A (1993) Transformation of Kluyveromyces lactis by electroporation. Appl. Environ. Microbiol 59, 2087-2092. [PubMed: 16348986]

(84). Kooistra R, Hooykaas PJJ, and Steensma HY (2004) Efficient gene targeting in Kluyveromyces lactis. Yeast 21, 781-792. [PubMed: 15282801]

(85). Janke C, Magiera MM, Rathfelder N, Taxis C, Reber S, Maekawa H, Moreno-Borchart A, Doenges G, Schwob E, Schiebel E, and Knop M (2004) A versatile toolbox for PCR-based tagging of yeast genes: new fluorescent proteins, more markers and promoter substitution cassettes. Yeast 21, 947-962. [PubMed: 15334558]

(86). Bahler J, Wu JQ, Longtine MS, Shah NG, McKenzie A. r., Steever AB, Wach A, Philippsen P, and Pringle JR (1998) Heterologous modules for efficient and versatile PCR-based gene targeting in Schizosaccharomyces pombe. Yeast 14, 943-951. [PubMed: 9717240]

(87). Gadaleta MC, Iwasaki O, Noguchi C, Noma KI, and Noguchi E (2013) New vectors for epitope tagging and gene disruption in Schizosaccharomyces pombe. BioTechniques 55, 257-263. [PubMed: 24215641]

(88). Chen SJ, Lin G, Chang KJ, Yeh LS, and Wang CC (2008) Translational efficiency of a non-AUG initiation codon is significantly affected by its sequence context in yeast. J. Biol. Chem 283, 3173-3180. [PubMed: 18065417]

(89). Bruckner A, Polge C, Lentze N, Auerbach D, and Schlattner U (2009) Yeast two-hybrid, a powerful tool for systems biology. Int. J. Mol. Sci 10, 2763-2788. [PubMed: 19582228] 
(90). Vidal M, and Fields S (2014) The yeast two-hybrid assay: still finding connections after 25 years. Nat. Methods 11, 1203-1206. [PubMed: 25584376]

(91). Teste MA, Duquenne M, Francois JM, and Parrou JL (2009) Validation of reference genes for quantitative expression analysis by real-time. BMC Mol. Biol 10, 99. [PubMed: 19874630]

(92). Xiao Q, Zhang F, Nacev BA, Liu JO, and Pei D (2010) Protein N-terminal processing: substrate specificity of Escherichia coli and human methionine aminopeptidases. Biochemistry 49, 55885599. [PubMed: 20521764]

(93). Stellberger T, Hauser R, Baiker A, Pothineni VR, Haas J, and Uetz P (2010) Improving the yeast two-hybrid system with permutated fusions proteins: the Varicella Zoster Virus interactome. Proteome Sci. 8, 8. [PubMed: 20205919]

(94). Dymond JS (2013) Explanatory chapter: quantitative PCR. Methods Enzymol. 529, 279-289. [PubMed: 24011054]

(95). Jozefczuk J, and Adjaye J (2011) Quantitative real-time PCR-based analysis of gene expression. Methods Enzymol. 500, 99-109. [PubMed: 21943894]

(96). Fraenkel DG (2011) Yeast Intermediary Metabolism, Cold Spring Harbor Laboratory Press, Plainview, NY.

(97). Santos DA, Shi L, Tu BP, and Weissman JS (2019) Cycloheximide can distort measurements of mRNA levels and translation efficiency. Nucleic Acids Res. 47, 4974-4985. [PubMed: 30916348]

(98). van Ooyen AJ, Dekker P, Huang M, Olsthoorn MM, Jacobs DI, Colussi PA, and Taron CH (2006) Heterologous protein production in the yeast Kluyveromyces lactis. FEMS Yeast Res. 6, 381392. [PubMed: 16630278]

(99). Lynch M (2007) The Origins of Genome Architecture, Sinauer Associates, Inc., Sunderland, MA. 


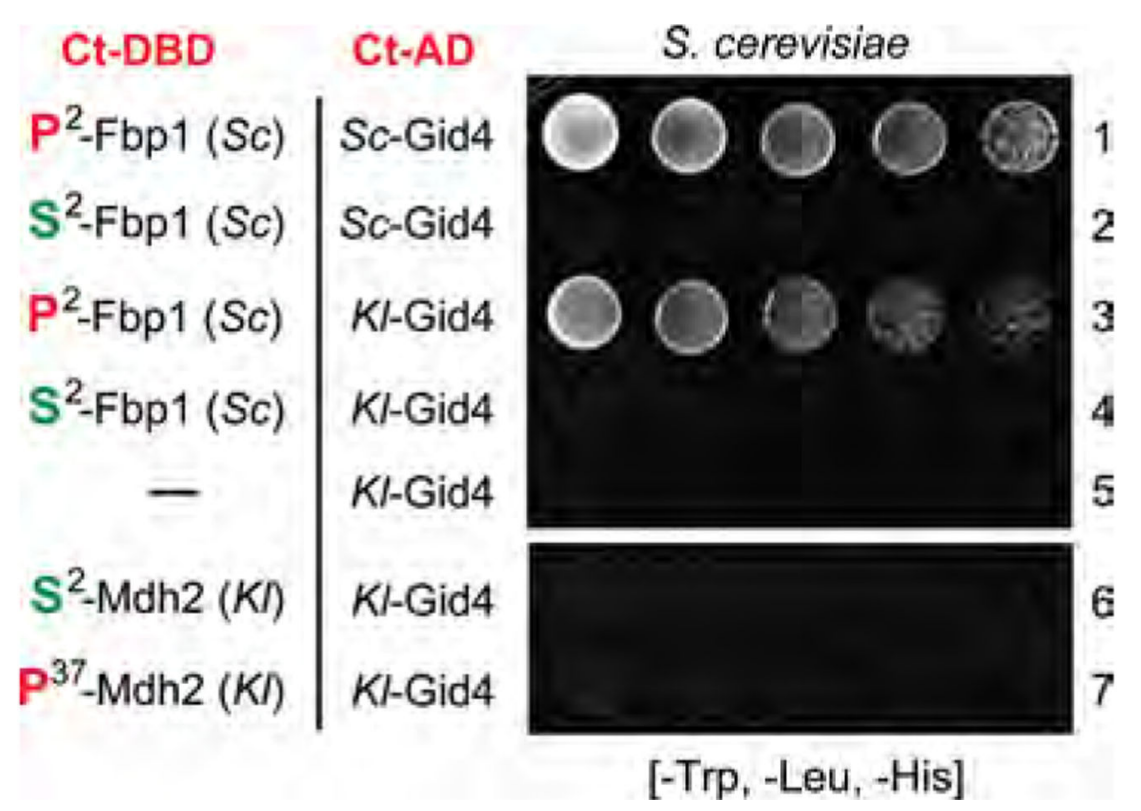

Figure 1.

Two-hybrid (Y2H) binding assays with $S$. cerevisiae and $K$. lactis proteins. The Pro and Ser residues (N-terminal in these test proteins) are colored red and green, respectively. In rows 1 and 2, as shown previously, ${ }^{24} S$. cerevisiae Gid4 binds to $S$. cerevisiae $\mathbf{P}-F b p 1$ but not to the otherwise identical $\mathbf{S}$-Fbp1 mutant that bears Nt-Ser. In rows 3 and 4, the same result but with $K$. lactis Gid4 (binding to $S$. cerevisiae $\mathbf{P}-F b p 1$ but not to $\mathbf{S}-F b p 1$ ). In row 5 , same as row 3 but in the absence of $\mathbf{S}-\mathrm{Fbp} 1$, a test for the absence of the $\mathrm{Y} 2 \mathrm{H}$ signal in the presence of $K$. lactis Gid4 alone. Analogous tests with $S$. cerevisiae Fbp1 alone were described previously. ${ }^{24}$ In rows 6 and 7, no detectable binding of $K$. lactis Gid4 to the wt $K$. lactis $\mathbf{S}$ Mdh2 protein and its N-terminally truncated $\mathbf{P}^{37}$-Mdh2 derivative (see Figure S2 and Results and Discussion). 


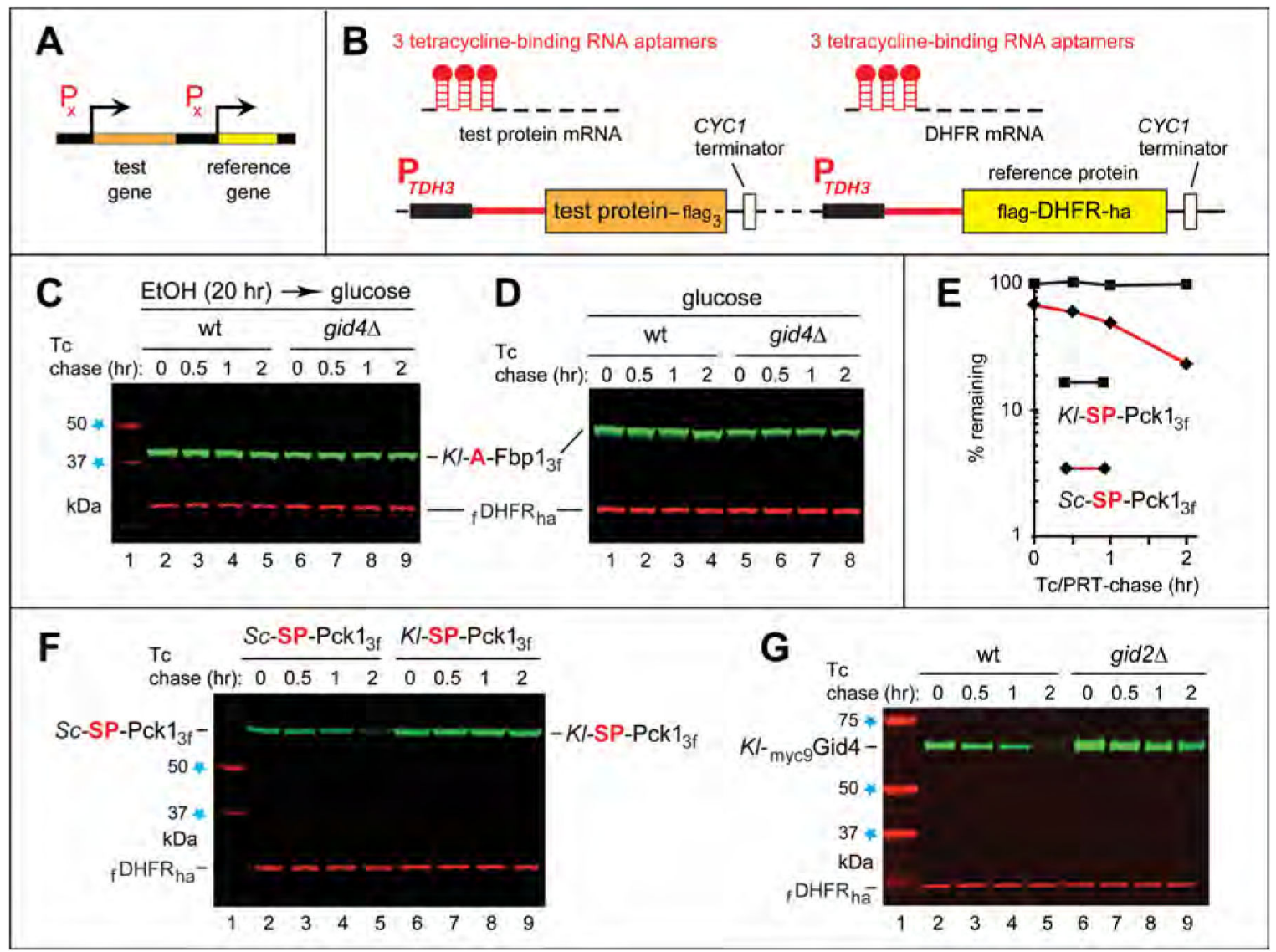

Figure 2.

Promoter reference technique and its use for degradation assays with $K$. lactis and $S$. cerevisiae proteins. (A and B) Tetracycline (Tc)-based promoter reference technique (see Results and Discussion and refs 24 and 40). (C) In lane 1, kilodalton markers. Tc/PRT chase was performed at $30{ }^{\circ} \mathrm{C}$ with wt $K$. lactis $\mathbf{A}-F b p 1_{3 \mathrm{f}}\left(K l-\mathbf{A}-\mathrm{Fbp} 1_{3 \mathrm{f}}\right)$ during transition from growth on ethanol (EtOH) to growth on glucose in wt (lanes 2-5) or gid4A (lanes 6-9) $S$. cerevisiae. The bands of $K l-\mathbf{A}-\mathrm{Fbp}_{3 \mathrm{f}}$ and $\mathrm{fDHFR}_{\mathrm{ha}}$ (a reference protein) are indicated on the right. (D) Same as panel C but with $S$. cerevisiae in glucose-containing medium. (E) Quantification of data in panel F. (F) In lane 1, kilodalton markers. Same as in panel D, in wt $S$. cerevisiae, but Tc/PRT chases with $S$. cerevisiae SP-Pck1 $3 \mathrm{f}\left(S c-\mathbf{S P}-\mathbf{P c k} 1_{3 \mathrm{f}}\right)$ (lanes 2-5) and with $K$. lactis $\mathbf{S P}-\mathrm{Pck} 1_{3 \mathrm{f}}\left(K\right.$ I-SP-Pck1$_{3 \mathrm{f}}$ ) (lanes 6-9) during the transition from growth on ethanol (EtOH) to growth on glucose (see Materials and Methods). (G) In lane 1, kilodalton markers. Tc/PRT chases, in wt (lanes 2-5) and in gid2A (lanes 6-9) S. cerevisiae grown in glucose-containing medium, with $K$. lactis Gid4 N-terminally tagged with the myc $_{9}$ epitope ( $\left.K l_{- \text {myc } 9} \mathrm{Gid} 4\right)$. Mouse DHFR (the indicated reference protein) was long-lived in $S$. cerevisiae irrespective of whether it contained its wt and Nt-acetylatable Met-Asp Nt sequence $^{21}$ (as in this study) or the Met-Pro Nt sequence (the latter was converted, cotranslationally, to the non-Nt-acetylatable Nt-Pro). 


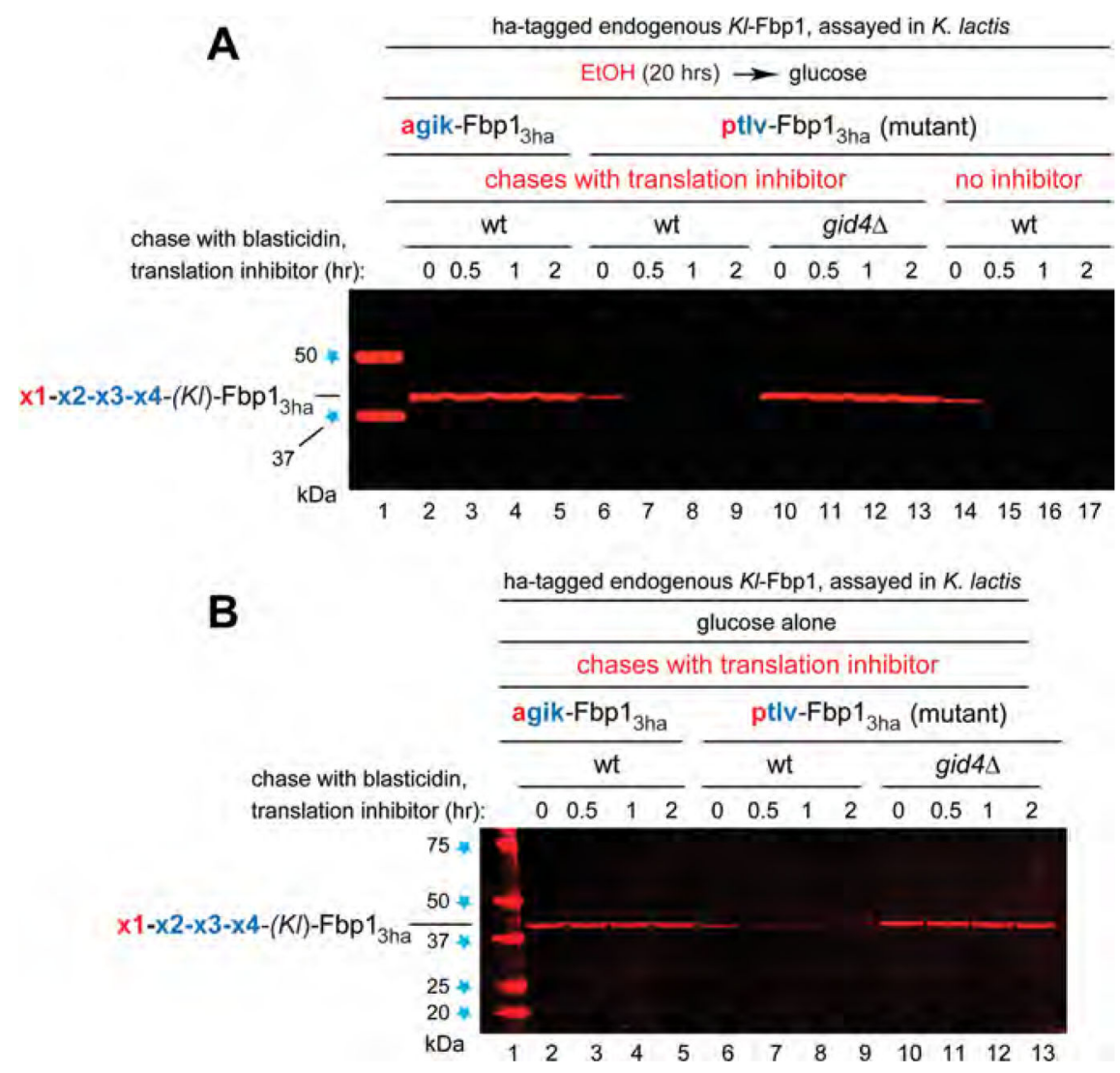

Figure 3.

Replacing the Nt-AGIC sequence of $K$. lactis Fbp1 with the Nt-PTLV sequence of $S$. cerevisiae Fbp 1 makes the resulting ptlv- Kl-Fbp1 short-lived in $K$. lactis. wt $K$. lactis $\mathrm{Fbp}_{3 \text { ha }}$, bearing the AGIK Nt sequence (after the removal of Nt-Met), was expressed in wt $K$. lactis from the native $\mathrm{P}_{F B P 1}$ promoter and was C-terminally tagged with the triple-ha tag. This $K$. lactis protein is denoted as agic- $K l$-Fbp $1_{3 \text { ha }}$ (after removal of Nt-Met). In a separate and otherwise wt $K$. lactis strain, the agic- $K l$-Fbp $1_{3 \text { ha }}$ mentioned above was replaced with ptlv- Kl-Fbp1 3 ha (after removal of Nt-Met), bearing the Nt-PTLV sequence of wt $S$. cerevisiae Fbp1 (see Results and Discussion). (A) In lane 1, kilodalton markers. In lanes 25 , wt $K$. lactis cells expressing (from the native $\mathrm{P}_{F B P 1}$ promoter) the endogenous wt $K$. lactis agic- $K l-F b p 1_{3 h a}$ (after removal of Nt-Met) were grown for $20 \mathrm{~h}$ in ethanol medium and thereafter shifted to glucose medium, followed by the blasticidin-based chase-degradation assay. Lanes 6-9, same as lanes 2-5 but with the otherwise wt $K$. lactis strain expressing ptlv- Kl-Fbp1 3 ha (after removal of Nt-Met), instead of agic- Kl-Fbp1 3 ha. Lanes $10-13$, same as lanes 6-9, but with gid4 $K$. lactis. Lanes 10-13, same as lanes 6-9, but in the absence of added blasticidin. (B) In lane 1, kilodalton markers. Lanes 2-5, same as lanes 2-5 in panel A, but the blasticidin-based chase was carried out with wt $K$. lactis cells [expressing, from the native $\mathrm{P}_{F B P 1}$ promoter, the endogenous wt $K$. lactis agic- $K l$-Fbp1 3 ha (after removal of Nt-Met)] grown in glucose alone. Lanes 6-9, same as lanes 2-5 but with the otherwise wt $K$. lactis strain expressing ptlv- Kl-Fbp1 3 ha (after removal of Nt-Met), instead of agic- $K 1$ -

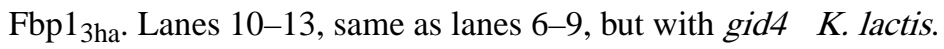

